\title{
Nanoporous and nonporous conjugated donor-acceptor polymer semiconductors for photocatalytic hydrogen production
}

\author{
Zhao-Qi Sheng ${ }^{1}$, Yu-Qin Xing ${ }^{1}$, Yan Chen ${ }^{1}$, Guang Zhang ${ }^{* 2}$, Shi-Yong Liu ${ }^{* 1}$ \\ and Long Chen ${ }^{2}$
}

\author{
Review \\ Address: \\ ${ }^{1}$ College of Materials, Metallurgical and Chemistry, Jiangxi University \\ of Science and Technology, Ganzhou, 341000, China, and \\ ${ }^{2}$ Department of Chemistry, Tianjin University, Tianjin 300072, China \\ Email: \\ Guang Zhang* - gzhdream@live.com; \\ Shi-Yong Liu* - chelsy@zju.edu.cn \\ * Corresponding author \\ Keywords: \\ ח-conjugated polymeric photocatalysts; donor-acceptor junctions; \\ nanostructure semiconductors; photocatalytic hydrogen production
}

\author{
Beilstein J. Nanotechnol. 2021, 12, 607-623. \\ https://doi.org/10.3762/bjnano.12.50 \\ Received: 12 March 2021 \\ Accepted: 13 June 2021 \\ Published: 30 June 2021 \\ This article is part of the thematic issue "New directions for nanoporous \\ materials".
}

Associate Editor: C. T. Yavuz

(C) 2021 Sheng et al.; licensee Beilstein-Institut.

License and terms: see end of document.

\begin{abstract}
Conjugated polymers (CPs) as photocatalysts have evoked substantial interest. Their geometries and physical (e.g., chemical and thermal stability and solubility), optical (e.g., light absorption range), and electronic properties (e.g., charge carrier mobility, redox potential, and exciton binding energy) can be easily tuned via structural design. In addition, they are of light weight (i.e., mainly composed of $\mathrm{C}, \mathrm{N}, \mathrm{O}$, and S). To improve the photocatalytic performance of CPs and better understand the catalytic mechanisms, many strategies with respect to material design have been proposed. These include tuning the bandgap, enlarging the surface area, enabling more efficient separation of electron-hole pairs, and enhancing the charge carrier mobility. In particular, donor-acceptor (D-A) polymers were demonstrated as a promising platform to develop high-performance photocatalysts due to their easily tunable bandgaps, high charge carrier mobility, and efficient intramolecular charge transfer. In this minireview, recent advances of D-A polymers in photocatalytic hydrogen evolution are summarized with a particular focus on modulating the optical and electronic properties of CPs by varying the acceptor units. The challenges and prospects associated with D-A polymer-based photocatalysts are described as well.
\end{abstract}

\section{Introduction}

To date, fossil fuels still are the predominant energy source around the world. This leads to severe environmental problems, such as the ever-worsening global warming due to the exces- sive emission of greenhouse gases and the pollution by poisonous gases and particles generated during the incomplete combustions of fossil fuels. In addition, fossil fuels are limited 
and will be depleted. Regarding clean and sustainable energy resources, in particular solar energy has become a candidate to eventually replace fossil fuels. Among the various strategies, hydrogen production by photocatalytic water splitting is emerging as a promising approach and hot research topic. Hydrogen is regarded as a clean and recyclable energy source, which can be obtained from water and, in turn, generates water as the only product after consumption [1-3]. Inspired by natural photosynthetic systems that can convert solar energy into chemical fuels, Fujishima and Honda [4] reported the first example of hydrogen production by photocatalytic water splitting in 1972, using $\mathrm{TiO}_{2}$ as the photocatalyst under ultraviolet-light irradiation. Since then, numerous semiconductors have been explored for photocatalytic hydrogen production (PHP) by water splitting, which are primarily inorganic materials, such as metal oxides and sulfides [5].

Inorganic photocatalysts, however, have some inherent drawbacks. Harsh synthetic conditions, such as high pressure and temperature, are required [5]. Moreover, many reported inorganic photocatalysts contain heavy metal elements, for example, $\mathrm{La}, \mathrm{Bi}$, and $\mathrm{Ta}$, which are often rare, toxic, and expensive [6]. Also, expensive noble metal-based cocatalysts (e.g., Pt) are required to improve the photocatalytic performance. As such, an ideal photocatalyst for water splitting reaction should fit the following criteria: suitable bandgap energy, high stability, wide light-absorption range, and sufficient catalytically active sites [7].

Conjugated polymers (CPs) are one of the most promising alternatives to the traditional inorganic photocatalysts. Their geometries and physical (e.g., chemical and thermal stability and solubility), optical (e.g., light absorption range), and electronic properties (e.g., charge carrier mobility, redox potential and exciton binding energy) can be easily tuned via structural design. In addition, they are of light weight (i.e., mainly composed of C, N, O, and S) [8-10]. In 1985, the first CP-based photocatalyst (i.e., poly(p-phenylene)) for PHP was reported, but did not attract much attention due to the low hydrogen evolution rate (HER) [11]. In 2009, Wang et al. reported a novel metal-free polymeric photocatalyst (i.e., graphitic carbon nitride $\left(\mathrm{g}-\mathrm{C}_{3} \mathrm{~N}_{4}\right)$ ), which could efficiently reduce protons to generate hydrogen under visible-light irradiation, for the first time. After that, $\mathrm{g}-\mathrm{C}_{3} \mathrm{~N}_{4}$ triggered substantial research interest [12-14] Various strategies have been developed to improve the PHP activity of $\mathrm{g}-\mathrm{C}_{3} \mathrm{~N}_{4}$, such as introducing heterojunctions [15-17], copolymerization [18-20], doping with other elements [21-23], and the control of end groups [24]. Meanwhile, various types of CPs have been applied for PHP, including conjugated porous polymers (CPPs) [25-27], linear conjugated polymers (LCPs) [28-30], conjugated triazine frameworks (CTFs) [31-33], and covalent organic frameworks (COFs) [34]. Notably, a record HER of up to $307 \mathrm{mmol} \cdot \mathrm{h}^{-1} \cdot \mathrm{g}^{-1}$ has been achieved with a pyrene-bithiophene-based porous polymer as the photocatalyst [35].

During PHP by water splitting, first, the photocatalyst is excited by photons, and photoexcited electrons hop into the lowest unoccupied molecular orbital (LUMO) or conduction band (CB), while holes remain in the highest occupied molecular orbital (HOMO) or valence band (VB). Second, the electron-hole pairs are transferred to the surface through thermodynamic driving forces and are captured by $\mathrm{H}^{+}$and a sacrificial electron donor (SED) in water, which eventually produces $\mathrm{H}_{2}[36,37]$. Accordingly, three important factors, that is, light-harvesting ability, mobility of the photogenerated charge carriers, and electron-hole separation efficiency, need to be considered simultaneously to design efficient photocatalysts.

Organic photocatalysts with narrow bandgap and high charge carrier mobility could, therefore, facilitate light harvesting and the reduction of protons [38]. In terms of structural design, D-A polymers are a good platform to narrow the bandgap, enhance the charge carrier mobility and promote electron-hole separation (Figure 1) by selectively tuning the donor and acceptor parts within the conjugated backbones $[39,40]$. The D-A architecture has been widely employed in high-performance organic optoelectronic devices, such as organic photovoltaics, organic field-effect transistors, nonlinear optics, and organic light-emitting diodes (OLEDs) [41]. However, it was only in recent years that researchers have started to use D-A design strategy to develop CP-based photocatalysts for PHP. As there is growing interests in this field, a timely review article about this area would be quite instructive and necessary [42].

This minireview article summarizes D-A-type conjugated polymers as photocatalysts for PHP, including LCPs, CPPs, CTFs, and COFs with a particular focus on modulating the electronaccepting segments, that is, triazine, pyridine, benzothiadiazole, dibenzothiophene-S,S-dioxide, and cyano moieties. By tailoring the functional groups and geometries of the polymer framework, the influence of different factors on the photocatalytic activity can be systematically investigated and, consequently, the structure-performance relationships are unveiled. Herein, the donor and acceptor fragments in the polymer structures are highlighted in red and blue, respectively.

\section{Review}

\section{Donor-acceptor conjugated polymers} Triazine-based conjugated polymers

$s$-Triazine and tri-s-triazine (heptazine), as the building blocks of carbon nitride, represent two of the most widely studied 


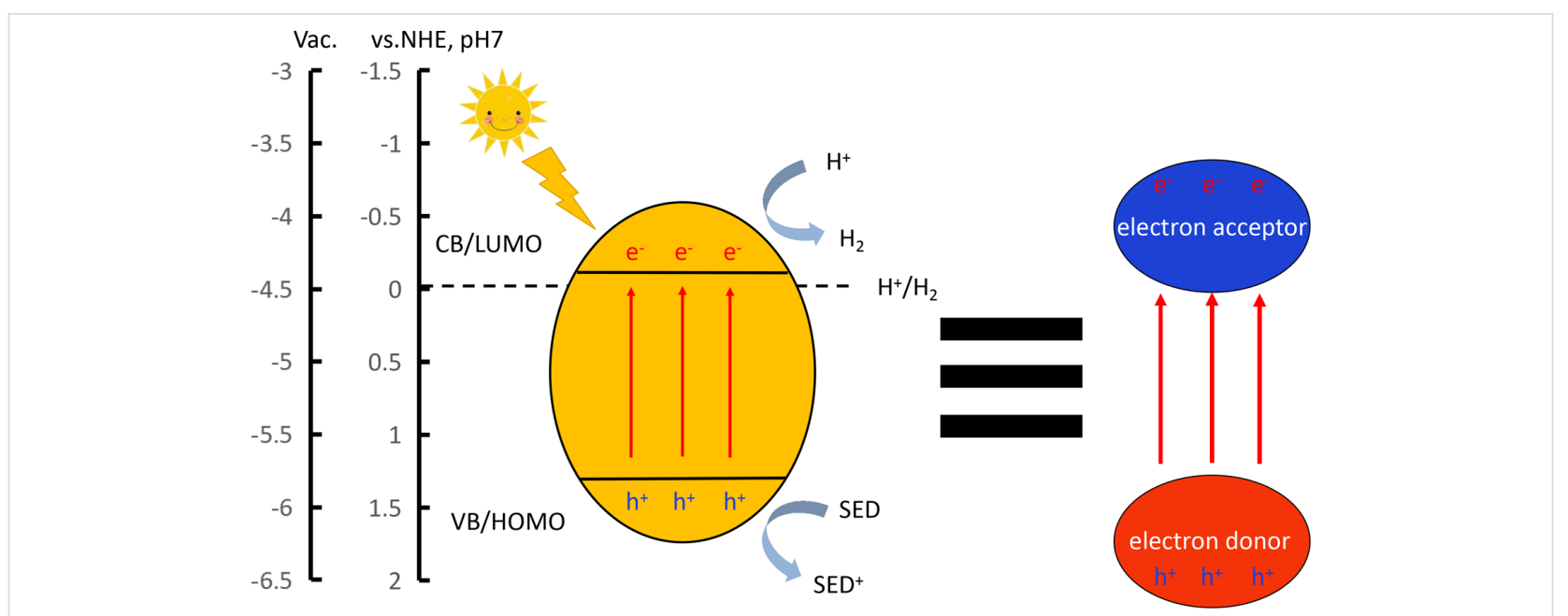

Figure 1: (Left) Schematic diagram of the mechanism of semiconducting catalyst-mediated photocatalytic hydrogen production (CB: conduction band VB: valence band, SED: sacrificial electron donors). (Right) Charge separation in a CP-based semiconductor via photoinduced $D \rightarrow A$ charge transfer.

acceptor units $[43,44]$. In contrast to the conventional trimerization of nitrile under harsh conditions [43], Tan et al. developed a new condensation reaction of aldehydes with amidines to construct covalent triazene frameworks (CTFs) under mild conditions [45]. They investigated the effects of donor units with different heteroatoms on the photocatalytic performance of CTFs. The carbazole-triazine-containing CTF P1 (Figure 2) triggered a strong intramolecular charge transfer (ICT) and achieved a high HER of $538 \mu \mathrm{mol} \cdot \mathrm{h}^{-1}(50 \mathrm{mg})$.

Bojdys and co-workers reported a series of CTFs with diverse functional moieties (e.g., heterocycles containing $\mathrm{S}$ and/or N) at the edges of the frameworks to delicately tune the bandgaps of conjugated polymers. Among them, three polymers, that is, P2, P3, and P4 (Figure 2), showed suitable bandgaps of ca. $2.2 \mathrm{eV}$, and conferred HERs of 4.72, 9.15, and $2.90 \mu \mathrm{mol} \cdot \mathrm{h}^{-1}$ (10 mg), respectively, under visible-light irradiation $[46,47]$. The bandgaps of the CTFs can be easily tuned to optimize the photocatalytic activity by introducing different functional groups. Besides using a single kind of electron acceptor, researchers also attempted to incorporate multiple electron acceptors to construct CPs for PHP. For instance, Thomas et al. [48] prepared several porous polymers with benzothiadiazole and heptazine moieties as the acceptors and an aminobenzene segment as the donor. By adjusting the molar ratio between the monomers, secondary $(\mathbf{P 5}$, benzothiadiazole/heptazine $=2: 3)$ or tertiary amine-linked polymers (P6, benzothiadiazole/heptazine = 4:3) (Figure 2) were obtained. $\mathbf{P 5}$ exhibited a smaller bandgap of $1.99 \mathrm{eV}$. Moreover, the photoluminescence spectra indicated an improved separation efficiency of photogenerated charges of P5. A stable $\mathrm{H}_{2}$ evolution rate of $32 \mu \mathrm{mol} \cdot \mathrm{h}^{-1}(20 \mathrm{mg})$ was achieved for HMP-3_2:3, which was several times higher than those of the triazine-amine-based P7 (Figure 2) and bulk g- $\mathrm{C}_{3} \mathrm{~N}_{4}$. Hence, incorporation of more than one kind of electron acceptors in the polymer structure could enhance the photocatalytic efficiency.

In addition, Tan et al. [49] developed several D-A CPs with carbazole (D), benzothiadiazole (A1) and triazine (A2) fragments. The photocatalytic activities of CPs with different D/A1 ratios were systematically investigated and compared. For example, $\mathbf{P 8}(\mathrm{D} / \mathrm{A} 1=3: 7)$ (Figure 2$)$ yielded the highest HER $\left(966 \mu \mathrm{mol} \cdot \mathrm{h}^{-1}, 50 \mathrm{mg}\right)$, which was consistent with the highest photocurrent response, smallest bandgap, and suppressed recombination of charge carriers in $\mathbf{P 8}$. The electron density distributions of three kinds of triazine-based fragments containing carbazole (M1), or both carbazole and benzothiadiazole (M2), and benzothiadiazole (M3) (Figure 3) were further calculated to support these results. M1 and M2 showed better charge separation than M3. In particular, M2 exhibited superior charge separation when considering spatial effects among the three fragments. Consequently, increasing the fraction of $\mathbf{M} 2$ in the polymers could be beneficial to the photocatalytic efficiency.

He et al. developed two pyrazole-triazine-based CTFs, that is, P9 (A-D-A) and P10 (D-A) (Figure 2) by a metal-free catalyzed approach [50]. Compared with P10, introducing a benzothiadiazole unit into $\mathbf{P 9}$ effectively reduced the optical bandgap from $2.94 \mathrm{eV}$ to the ideal value of $2.33 \mathrm{eV}$. They further probed the influence of substituting the $\mathrm{S}$ atom in the benzothiadiazole group with $\mathrm{O}$ or Se atoms on the optoelectronic and photocatalytic properties of the CTFs P11 and P12 (Figure 2) [51]. Introducing an $\mathrm{O}$ atom boosted the ICT and electron-hole separation due to the higher electron negativity; but it lowered the LUMO level, which as a result, suppressed the PHP reaction. Incorporating a Se atom led to a redshifted 


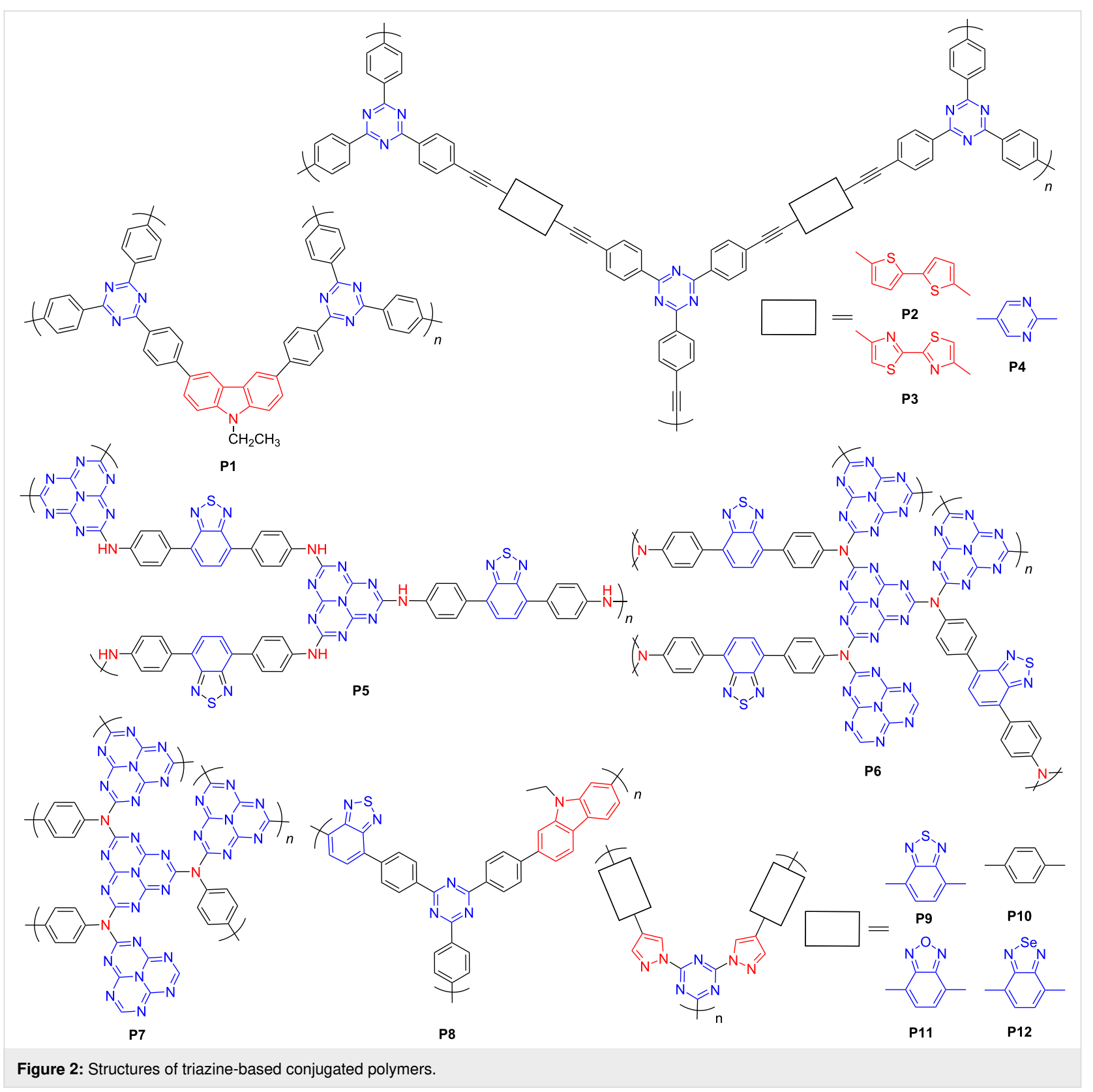

light absorption, but decreased the charge carrier mobility due to the reduced aromaticity of the architecture. Consequently, the HERs declined in both cases. These results reveal that slight structural changes could significantly modulate the properties and photocatalytic activities of CTFs.

\section{Pyridine-based conjugated polymers}

Pyridine, as a nitrogen-containing benzene analogue, was incorporated into linear conjugated polymers as early as in the 1990s. The CPs exhibited distinctive photocatalytic activity for $\mathrm{H}_{2}$ production under visible light [52]. With the extensive studies of nitrogen-rich triazine- and heptazine-based photocatalysts for hydrogen production, pyridine and its derivatives as nitrogen- containing acceptors have attracted great interest again, and D-A architectures for photocatalytic water splitting were synthesized.

In 2015, Lotsch et al. [53] reported four COFs with benzene, pyridine, pyrimidine, and triazine as the core to disclose the effects of nitrogen atoms on the photocatalytic activities of these COFs. It showed a linear correlation between HER and the content of nitrogen atoms in the COF skeleton. However, HER is affected by the interplay of several factors, including surface area, light absorption range, crystallinity, charge transfer, and separation. Two azine-linked COFs with three pyridine segments neighboring the central benzene or triazine 

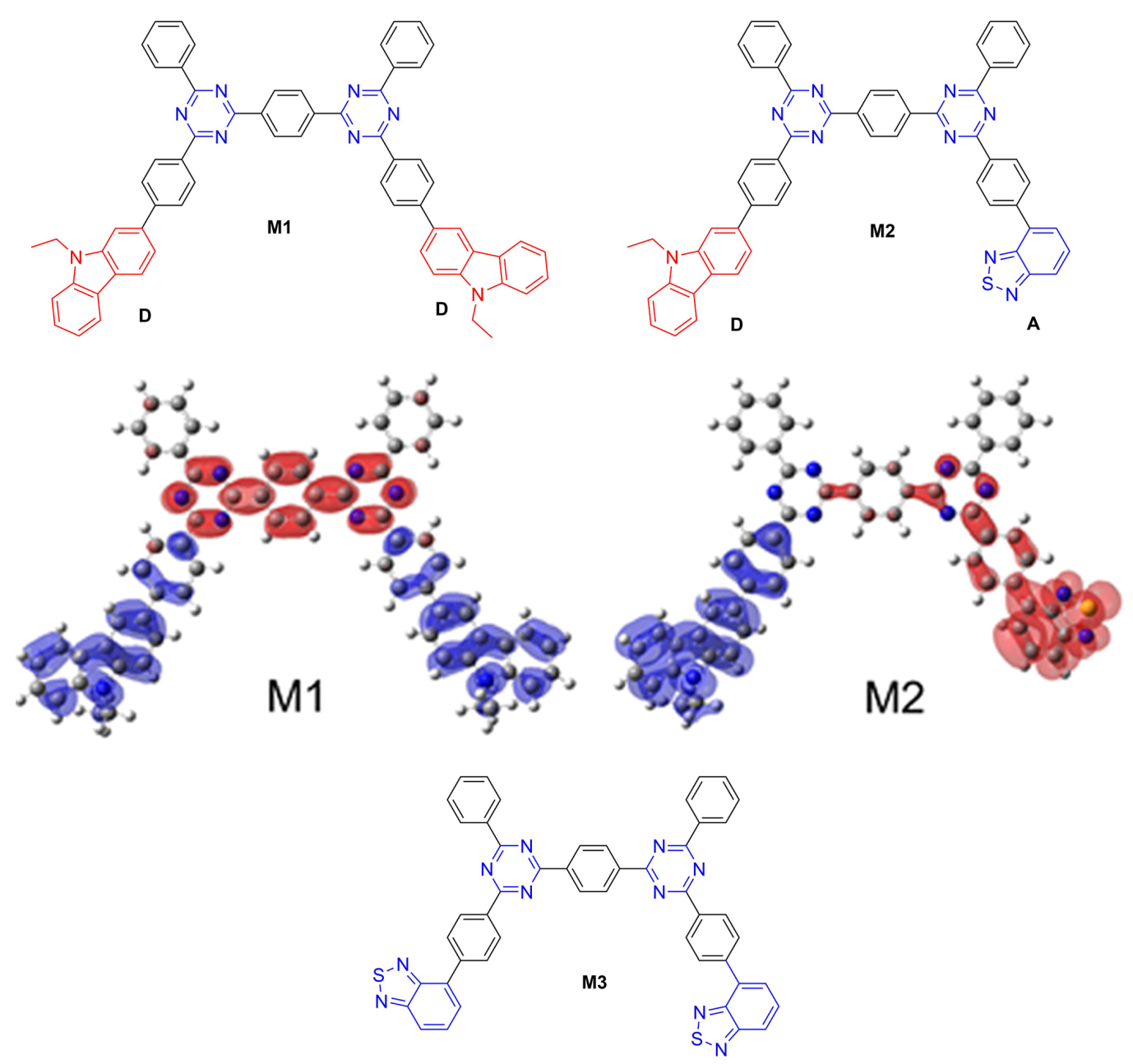

A

A

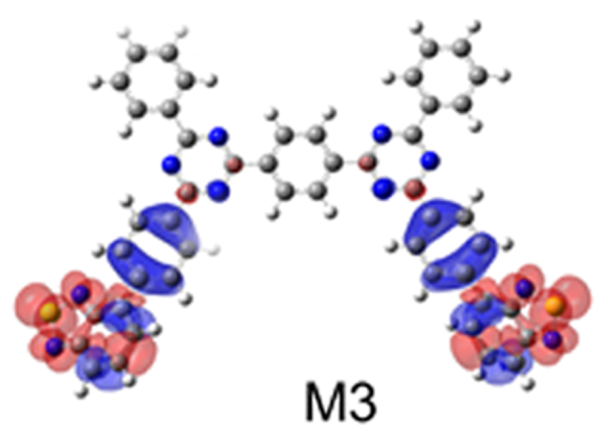

Negative of electron density difference between the first excited state and the ground state

Positive of electron density difference between the first excited state and the ground state

Figure 3: Proposed model fragments and electron density differences of M1-M3 in P8. Adapted with permission from [49]. Copyright (2019) American Chemical Society. This content is not subject to CC BY 4.0.

fragment were prepared to make comparisons, that is, the 1,3,5tri(pyridin-2-yl)benzene based COF P13 and the benzenetriazine-based P14 (Figure 4). Both of them showed a similar AA eclipsed stacking in the crystal structures, but the lower symmetry of $\mathbf{P 1 3}$ resulted in worse crystallinity. Particularly, the $\mathrm{D}-\mathrm{A}$ interactions between the pyridine and the benzene rings gave rise to disorder and reduced crystallinity even further. As a result, the HER of $\mathbf{P 1 3}\left(0.42 \mu \mathrm{mol} \cdot \mathrm{h}^{-1}, 5 \mathrm{mg}\right)$ was one order of magnitude lower than that of P14 $\left(8.52 \mu \mathrm{mol} \cdot \mathrm{h}^{-1}\right.$, $5 \mathrm{mg}$ ) [53]. 


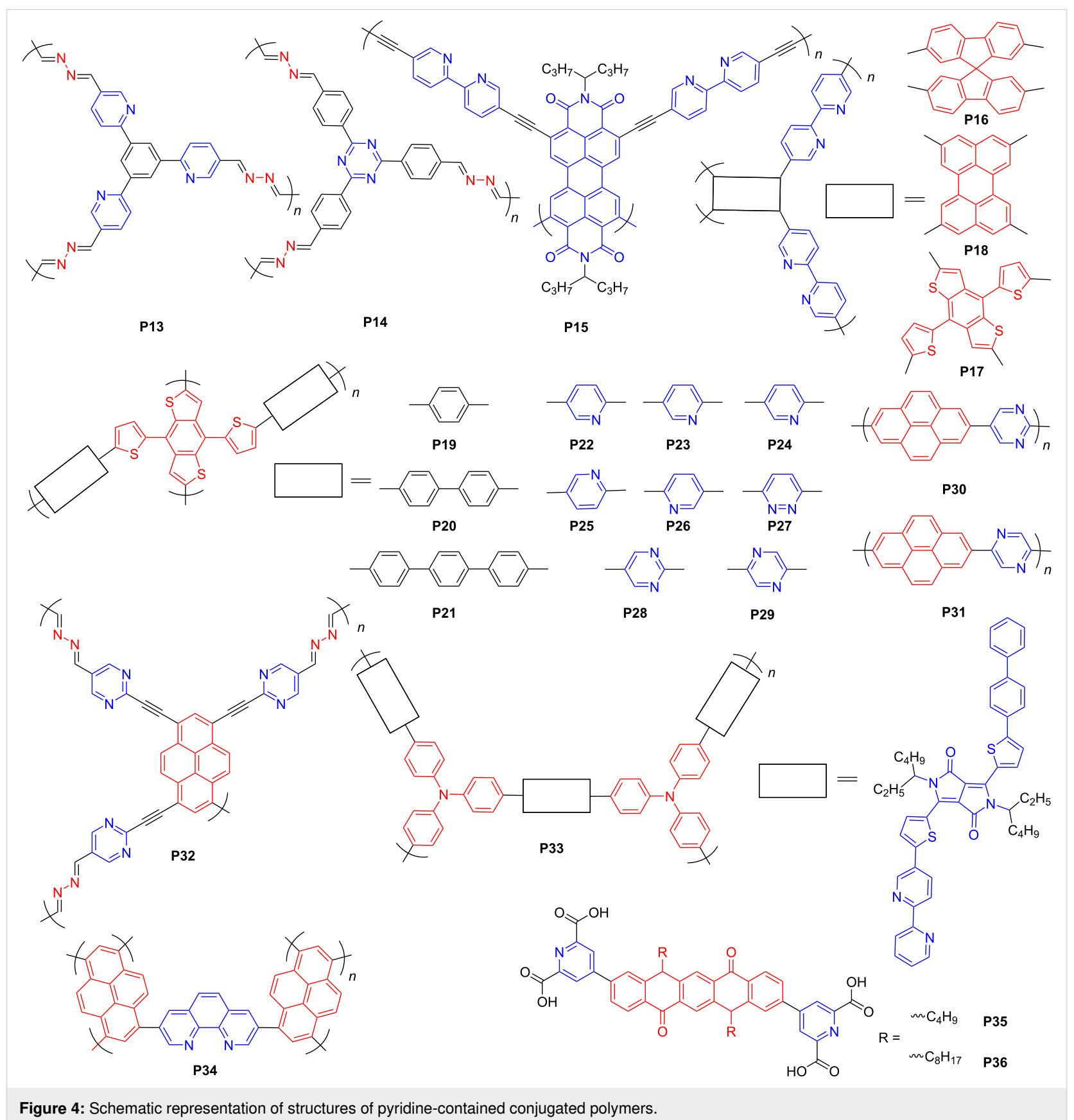

Cai et al. [54] reported a series of perylene diimide (PDI)-based n-type porous CPs (Figure 4). The HERs of the polymers with phenyl or biphenyl moieties as donors were lower than that of the pure acceptor polymer P15 $\left(7.2 \mu \mathrm{mol} \cdot \mathrm{h}^{-1}, 3.5 \mathrm{mg}\right)$. Although the benzene group could serve as a weak donor in some cases, it is difficult to render effective D-A interactions. For instance, $\mathrm{Yu}$ and co-workers [55] combined electron-deficient PDI or electron-rich chromophores (including spirofluorene, perylene, and 4,8-di(thiophen-2-yl)benzo[1,2- $\left.b: 4,5-b^{\prime}\right]$ dithiophene (DTBDT) with bipyridine moieties to form several porous polymers (P15-P18) (Figure 4) to investigate the rela- tionship between D-A interactions and photocatalytic properties. PDI-containing polymers, such as P15, normally confer smaller HERs than the others. P18, composed of strong electron-donating and bipyridine segments, rendered the best HER, which was attributed to its enhanced light absorption, better wettability, and more efficient charge separation. Based on DTBDT monomer, many porous polymers (P19-P29) (Figure 4) were further prepared to study the effects of different acceptors on the photocatalytic performance during water splitting [56]. PCPs incorporating nitrogen-containing heterocycles showed a better photocatalyt- 
ic performance than those with oligophenylene moieties, which is due to the favorable internal polarization and coordinating sites rendered by nitrogen-containing heterocycles. Among them, the DTBDT-pyrazine-based P29 achieved the best HER of $106.9 \mu \mathrm{mol} \cdot \mathrm{h}^{-1}(12 \mathrm{mg})$ due to the suitable $\mathrm{N}$ substitution.

Pyrene as a well-known chromophore has been widely used in OLEDs and fluorescent probes due to its high photoluminescent quantum yield. Jiang et al. [57] introduced various sorts of nitrogen-containing fragments in pyrene-based polymers to investigate their photocatalytic performance, for example, P30 and P31 (Figure 4). Interestingly, different from the above examples, the pyrimidine-containing P30 $\left(18.7 \mu \mathrm{mol} \cdot \mathrm{h}^{-1}, 50 \mathrm{mg}\right)$ exhibited a much higher HER than $\mathbf{P 3 1}$ with pyrazine moieties (8.6 $\left.\mu \mathrm{mol} \cdot \mathrm{h}^{-1}, 50 \mathrm{mg}\right)$. Lotsch et al. [58] also developed several pyrene-based COFs with peripheral nitrogen-containing or nitrogen-free aromatic units, among which the pyrene-pyrimidine-based P32 (Figure 4) with the lowest nitrogen content showed the highest HER. Nitrogen heterocycles within polymers could optimize wettability, bandgap, charge transport, and separation.

Motivated by the planar configuration and strong electronacceptor capability of diketopyrrolopyrrole (DPP) [59-61], Li and co-workers [62] combined DPP with triphenylamine and bipyridine groups to synthesize D-A polymers. A HER of $9.73 \mu \mathrm{mol} \cdot \mathrm{h}^{-1}$ (3.5 mg) was achieved for P33 (Figure 4) due to the wide spectral range of the photoresponse. The apparent quantum yield (AQY), as a vital experimental parameter for photocatalytic performance, exceeded $9 \%$ at $420 \mathrm{~nm}$, which is, to date, the highest among all reported conjugated polymerbased photocatalysts. In addition, phenanthroline-pyrene-based D-A polymers were studied [63], with polymer P34 (phenanthroline/pyrene $=1 / 3$ ) (Figure 4) exhibiting the highest HER of $42 \mu \mathrm{mol} \cdot \mathrm{h}^{-1}(10 \mathrm{mg})$. Additionally, Hua et al. [64] constructed two D-A supramolecular architectures with different alkane chains, that is, $\mathbf{P 3 5}$ and $\mathbf{P 3 6}$ with n-butyl and n-octyl chains, respectively (Figure 4), by self-assembling quinacridone and pyridine-2,6-dicarboxylic acid. It was revealed that the longer alkyl chain was harmful to the D-A interactions in CPs. Thus, nitrogen-containing aromatic segments can effectively mediate the internal polarization of the polymeric framework and thus enhance the PHP performance.

\section{Benzothiadiazole-based conjugated polymers}

The benzothiadiazole (BT) moiety as a strong electron acceptor features high planarity and good wettability due to incorporating $\mathrm{N}$ and $\mathrm{S}$ atoms. In 2016, Wang and co-workers [65] investigated the properties of a linear conjugated polymer and a $3 \mathrm{D}$ counterpart by varying the substitution position on the benzene ring. Interestingly, the linear polymer exhibited more effective D-A interactions than the 3D counterpart due to the enhanced conjugation of the former with a planar architecture.

Two ethynyl-linked benzene-benzothiadiazole-based porous polymers, that is, P39 and P40 (Figure 5) were synthesized to investigate the influence of fluorine substitution at BT on the charge carrier mobility and catalytic activity [66]. The mechanism of proton-coupled electron transfer (PCET) (Figure 6) was offered. It suggests for both linear and 3D polymers that single meta-F substitution renders a higher photocatalytic activity than double F substitution, and the polymer with the methoxy group at the meta site and the $\mathrm{F}$ atom at the para site yields the highest HER due to the excellent mobility of photogenerated charge carriers and the broad light absorption range. DFT calculations also verified that incorporating $\mathrm{F}$ on the para carbon atom of the BT unit strengthens the intermolecular interactions and thus enhances the charge transfer effect among the polymer chains. This is due to the interaction between two $\mathrm{p}$ orbitals from the meta carbon atom on one molecule and a $\mathrm{N}$ atom on the other. In addition, a methoxy group at the meta position intensified the intermolecular interaction, which, however, was weakened by $\mathrm{F}$ substitution at the meta position. Consequently, the linear P39 (Figure 5) with both methoxy group and F on BT afforded the highest HER of $399 \mu \mathrm{mol} \cdot \mathrm{h}^{-1}$ (30 mg). This suggests that selectively functionalizing the BT unit with F could greatly enhance the charge transfer in BT-based polymers.

Besides fluorine substitution, several halogenated BT-based imine-linked COFs were reported by Chen et al. [67] to investigate the effects of halogen atoms on the photocatalytic performance. The $\mathrm{Cl}$-substituted COF with pyrene and BT exhibited the best HER $\left(177.50 \mu \mathrm{mol} \cdot \mathrm{h}^{-1}, 20 \mathrm{mg}\right)$ due to low charge recombination and strong photoinduced charge transfer. Furthermore, DFT calculations (Figure 7) indicated that incorporating halogen atoms in both $\mathbf{P 4 3}$ and $\mathbf{P 4 4}$ (Figure 5) reduces the energy barrier for forming $\mathrm{H}^{*}$ intermediates on polymer surface. Consequently, halogen substitution on the polymer is an approach to evoke enhanced charge separation and improve the HER of CPs.

In 2018, Jiang et al. [68] systematically studied the effects of $\pi$-linking groups, that is, benzene or biphenyl moieties in pyrene-benzothiadiazole-based polymers, for example, $\mathbf{P 4 5}$ (Figure 5). The D- $\pi-\mathrm{A}$-type compound $\mathbf{P 4 5}$ possesses an extended $\pi$-conjugation along the backbone and consequently has an enlarged visible-light absorption and enhanced electronic conductivity compared with $\pi$-linker-free pyrene-benzothiadiazole-based polymers. After deposition of Pt as the cocatalyst, P45 exhibited the most prominent photocatalytic activity for $\mathrm{H}_{2}$ evolution $\left(29.6 \mu \mathrm{mol} \cdot \mathrm{h}^{-1}, 100 \mathrm{mg}\right)$ under visible light. These 


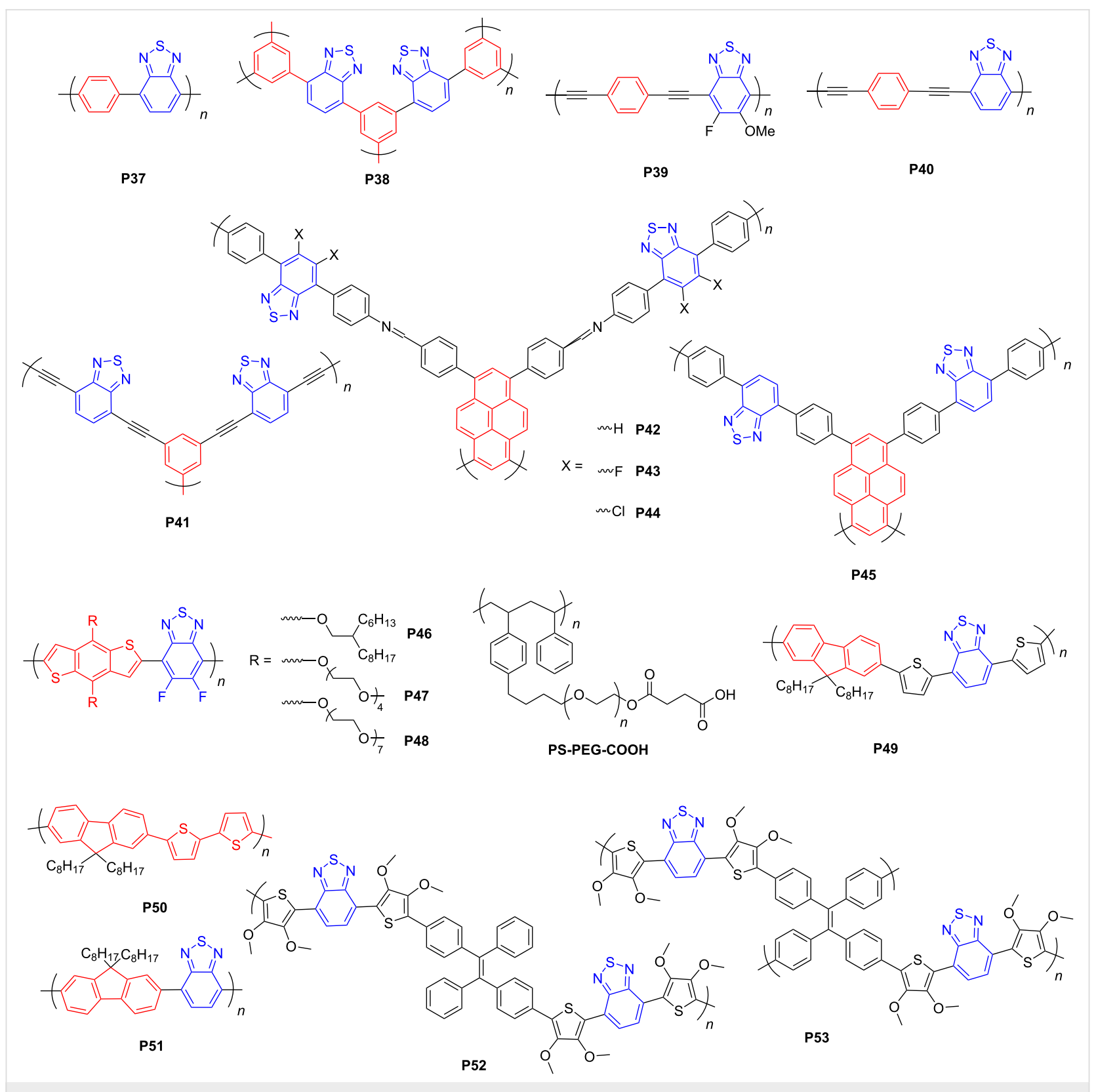

Figure 5: Schematic representation of structures of benzothiadiazole-based conjugated polymers.

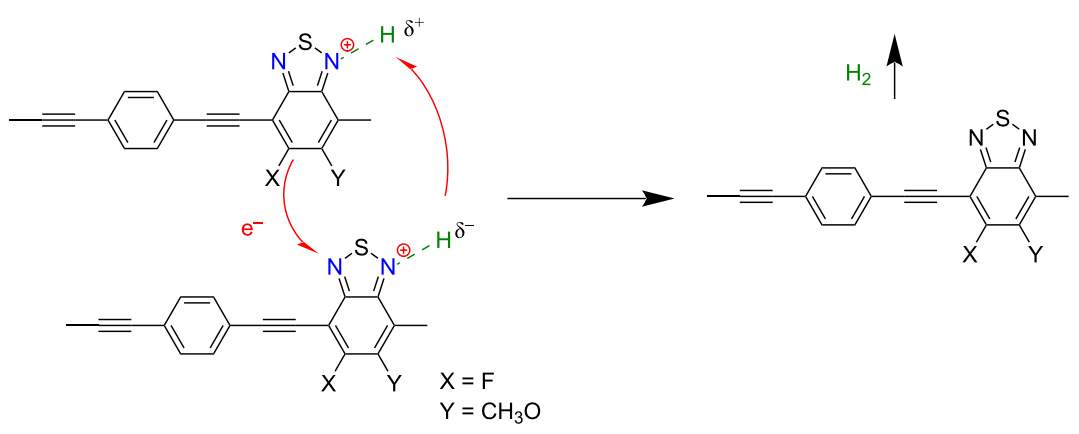

Figure 6: The mechanism of PCET-enhanced $\mathrm{H}_{2}$ formation; see [66]. 
(a)

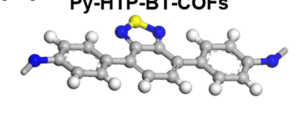

$\mathrm{S}_{0}$

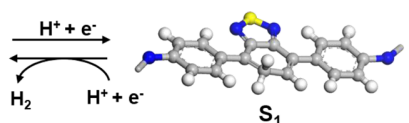

$\mathrm{s}_{1}$

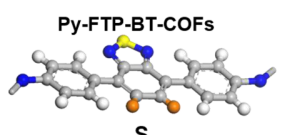

$\mathrm{S}_{0}$

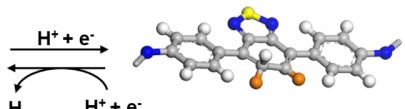

$\mathrm{S}_{1}$

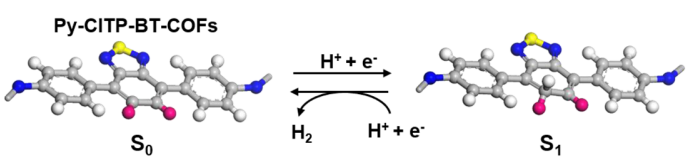

(b)

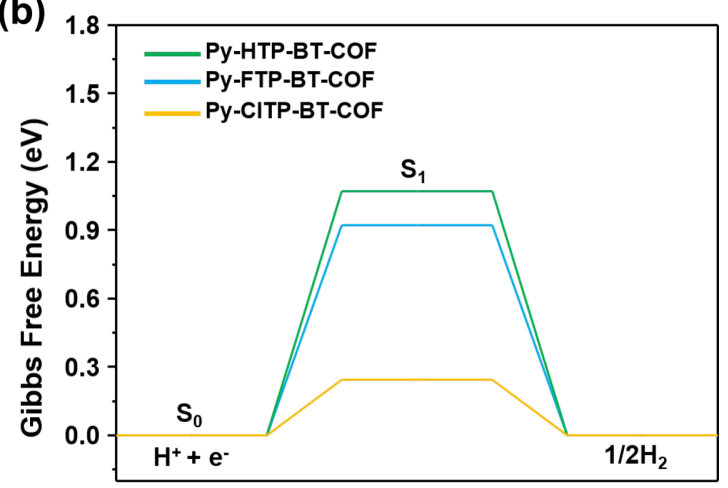

Reaction Coordinate

Figure 7: (a) Proposed reaction pathway for $\mathrm{H}_{2}$ evolution (single-site reaction) on the halogen-substituted carbon atom of P42-P44 (grey: C; white: $\mathrm{H}$; yellow: S; blue: $\mathrm{N}$; orange: $\mathrm{F}$; pink: $\mathrm{Cl}$ ). (b) Free-energy diagrams for $\mathrm{H}_{2}$ evolution via a single-site reaction pathway at $\mathrm{O} \mathrm{V}$ vs $\mathrm{RHE}$ on the halogensubstituted carbon atom of COFs. Reproduced from [67]. Copyright (c) 2020 Wiley-VCH GmbH. Used with permission from Chen et al., Modulating Benzothiadiazole-Based Covalent Organic Frameworks via Halogenation for Enhanced Photocatalytic Water Splitting, Angew. Chem. Int. Ed., John Wiley and Sons. This content is not subject to CC BY 4.0.

results suggest that the $\mathrm{D}-\pi-\mathrm{A}$ architecture might be better than the conventional D-A counterpart for designing high-performance polymer-based photocatalysts for $\mathrm{H}_{2}$ evolution.

Although the BT group can increase the wettability of polymers [50], most BT-based polymers are difficult to disperse in water. To overcome the issue of poor dispersibility of BT-based polymers, Huang et al. [69] synthesized two BT-based linear CPs with oxygen-containing branched side chains. Different from long alkyl chains, the polymers incorporating the oligo(ethylene glycol) side chains (P48) (Figure 5) showed considerably improved charge separation and transport and could be dispersed in water without any co-solvent. Similar to the $\mathrm{N}$ atoms in $\mathrm{BT}$ units, oxygen atoms can also adsorb $\mathrm{H}^{+}$in water to form the polymer/water interface.

Tian et al. [70] prepared several BT-based polymer dots (Pdots) with functionalized polystyrene (PS-PEG-COOH) (Figure 5) to improve the wettability of polymers. In contrast to the pristine BT-based polymers (P49-P51) (Figure 5), the Pdots were dispersed in water. The Pdots of $\mathbf{P 4 9}$ rendered one of the highest HER $\left(150 \mu \mathrm{mol} \cdot \mathrm{h}^{-1}, 3 \mathrm{mg}\right)$ among all Pdots, which was attributed to the water solubility, broad light absorption and abundant catalytic sites of BT-based Pdots. In addition, Hu et al. [71] synthesized hyper-branched Pdots by co-assembling pristine polymers (P52 and P53) and hydrophilic PEG $_{45}{ }^{-b}-$ PMMA $_{103}$ (Figure 5). The hyperbranched Pdots yielded higher HERs (as high as $16.8 \mu \mathrm{mol} \cdot \mathrm{h}^{-1}$ (20 mg) for P53) than the linear Pdot P52, due to the shortened charge transport pathway, $3 \mathrm{D}$ transport, and more negative reduction potentials of the hyperbranched Pdots. Araujo et al. [72] studied several BT-containing small molecules with A-D-A architectures through theoretical calculations. They found that small molecules could also mediate photocatalytic water splitting into hydrogen and oxygen.

\section{Dibenzothiophene-S,S-dioxide-based conjugated polymers}

Recently, dibenzothiophene- $S, S$-dioxide (FSO) has been extensively applied to construct D-A CPs due to its planar architecture, matched energy levels, and strong electron withdrawal property. The sulfonyl groups could not only increase the wettability through the $\mathrm{O} \cdots \mathrm{H}$ hydrogen bonding, but also function as the sites for photocatalytic proton reduction in water [73]. Cooper and co-workers [74] first reported FSO-based CPs as catalysts for PHP in 2016. The linear FSO-phenylbased polymer P54 (Figure 8) yielded a moderate HER of $92 \mu \mathrm{mol} \cdot \mathrm{h}^{-1}(25 \mathrm{mg})$ under visible light.

Subsequently, Wang et al. [75] combined FSO with biphenyl, dibenzothiophene, or fluorene segments to construct D-A CPs (P55-P57). Experimental studies showed that the dibenzothiophene-containig polymer $\mathbf{P 5 6}$ (Figure 8) exhibited an outstanding AQY of $6.8 \%$ at $420 \mathrm{~nm}$. Both dibenzothiophene and fluorene moieties possess planar structures compared with biphenyl group, yet dibenzothiophene has a more extended conjugation than fluorene due to the existence of a saturated 9-C atom in fluorene. Therefore, P56 with the most extended conjugation facilitated more efficient charge transfer and separation. High planarity and extended conjugation of a polymer skeleton are crucial to realize efficient photocatalytic water splitting. Liu et al. [76] integrated FSO with fluorene or 9,9-diphenylfluorene segments to prepare two D-A polymers (P57 and P58) (Figure 8 ). The photocatalytic activities of these $\mathrm{D}-\mathrm{A}$ polymers increased with enhancing the planarity of the polymer backbones, due to improved charge transfer and increased light 


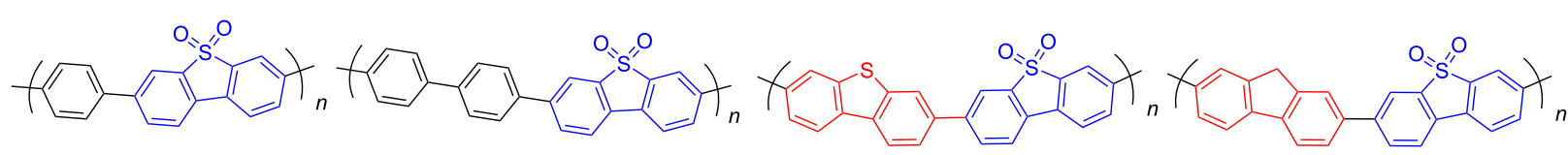

P54

P55

P56

P57

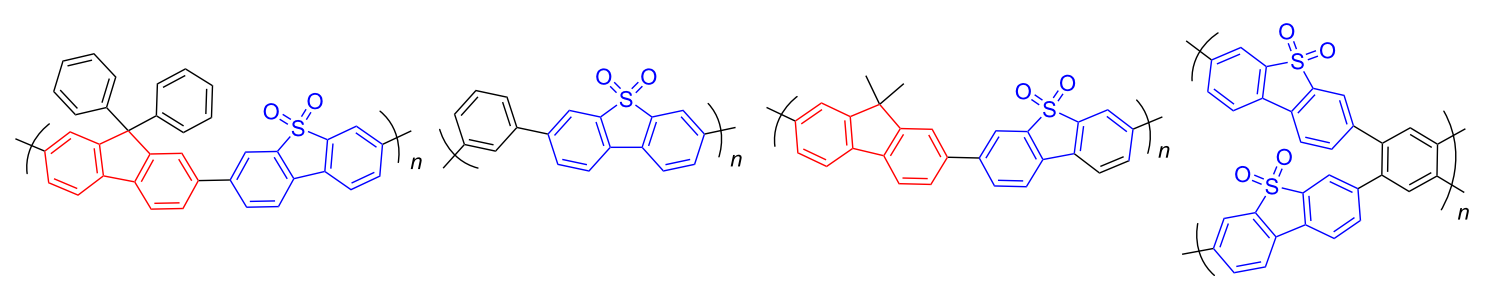

P58

P59

P60

P61

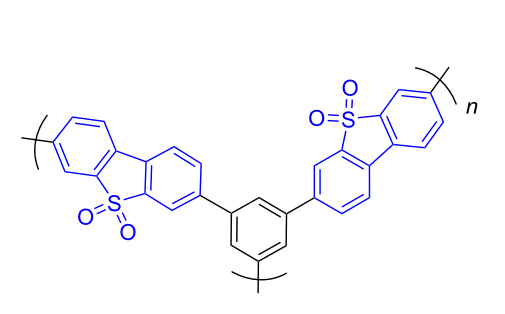

P62

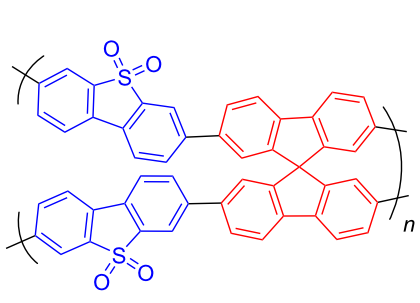

P63

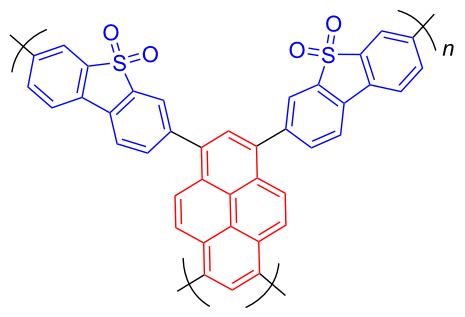

P64

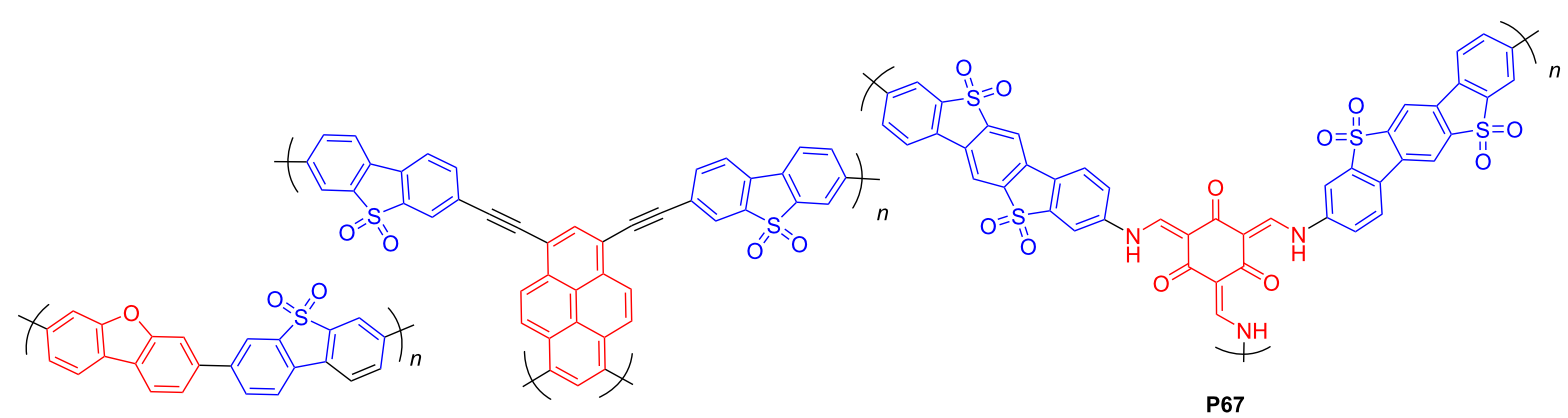

P65

P66

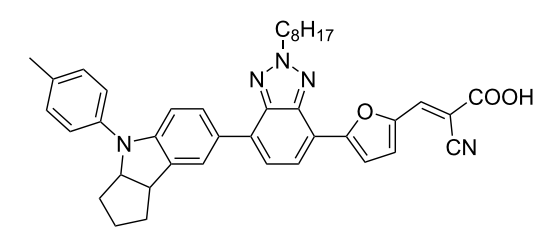

WS5F

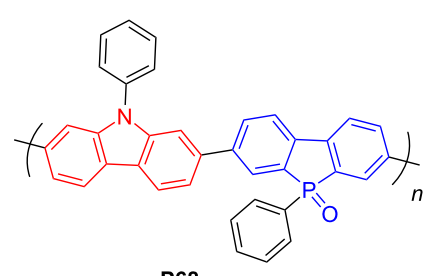

P68

Figure 8: Schematic representation of structures of dibenzothiophene-S,S-dioxide-based CPs.

absorption in more planar conjugated systems. Therefore, the fluorene-containing polymer P57 (Figure 8) exhibited the best performance among the three D-A polymers with a HER of $50.4 \mu \mathrm{mol} \cdot \mathrm{h}^{-1}(10 \mathrm{mg})$.

Comparing the photocatalytic performance of linear CPs and their 3D counterparts, many research articles claimed that linear CPs render higher HERs than porous CPs due to the superior charge carrier mobility of linear polymers $[65,66,71]$. However, Cooper et al. [77] reasoned that porous polymers might be better than linear counterparts to promote photocatalytic hydrogen evolution as long as the charge carrier transport was not compromised by the 3D structures. This claim was exemplified by the 9,9'-spirobifluorene-FSO-based porous polymer $\mathbf{P 6 3}$ (Figure 8), which exhibited the best catalytic performance under visible light among the linear and porous polymers in that work, 
with a HER of $77.65 \mu \mathrm{mol} \cdot \mathrm{h}^{-1}(25 \mathrm{mg})$. Jiang et al. [78] reported two pyrene-FSO-based porous CPs with different linking positions with respect to dibenzothiophene- $S, S$-dioxide, for example, the 3,7-position-linked polymer P64 (Figure 8). P64 afforded a higher HER of $284.85 \mu \mathrm{mol} \cdot \mathrm{h}^{-1}(50 \mathrm{mg}$ ) under visible light without cocatalyst than the 2,8-position-linked compound due to the more extended conjugation and enhanced coplanarity of P64. As outlined above, judiciously selecting donor and acceptor components and designing 3D polymers could give rise to impressive performances during PHP.

Recently, Cooper and co-workers studied the effects of replacing the $\mathrm{C} 9$ of the fluorene moiety in polymer P57 with heteratoms [79]. The oxygen-containing dibenzo[ $[b, d]$ furan-FSObased polymer P65 (Figure 8) showed a higher HER $\left(147.1 \mathrm{~mol} \cdot \mathrm{h}^{-1}, 25 \mathrm{mg}\right.$ ) than $\mathbf{P 5 7}$ under visible light. This was attributed to the improved wettability of $\mathbf{P 6 5}$ induced by the additional electronegative $\mathrm{O}$ atom and to the decreased ionization potential of trimethylamine (TEA) accelerating its oxidation through the higher driving force of $\mathbf{P 6 5}$ for overall TEA oxidation [79]. In addition, Wang et al. [80] prepared a porous polymer with pyrene core and $\mathrm{F}$ atom-functionalized FSO segments (Figure 8). Different from the BT-based polymers mentioned above, incorporating $\mathrm{F}$ atoms at the FSO moiety resulted in a decreased HER. The authors reasoned that $\mathbf{P 6 4}$ with the sulfonyl group could efficiently concentrate as well as output electrons and build excellent electron-output "tentacles" and therefore increase the HER. Chen et al. [81] reported an ethynyl-bridged FSO-pyrene-based polymer (P66) (Figure 8) to further extend the conjugation. The water contact angle measurements showed that the wettability was enhanced with increasing the content of FSO units. $\mathbf{P 6 6}$ achieved an AQY of $8.5 \%$.

Cooper et al. [82] systematically investigated the influence of plasma treatments on conjugated polymers as photocatalysts, for example, the fluorine-FSO-based P60 (Figure 8). For P60, a short time of plasma treatment significantly enhanced the wettability and photocatalytic performance due to the plasma oxidizing the polymer. In addition, they [83] prepared a crystalline benzo[1,2- $b: 4,5-b$ ']bis[1]benzothiophene sulfone-containing covalent organic framework (P67) (Figure 8), which exhibited a higher HER than its amorphous or semicrystalline counterparts. Dye sensitization further enhanced the photocatalytic activity of P67. Remarkably, incorporating a near-infrared absorbing dye (WS5F) into P67 (252.5 $\mu \mathrm{mol} \cdot \mathrm{h}^{-1}, 25 \mathrm{mg}$ ) further improved the HER to $497.5 \mathrm{mmol} \cdot \mathrm{h}^{-1}(25 \mathrm{mg})$, which was attributed to the enhanced light absorption and photoinduced WS5F-to-P67 charge transfer. Similar to the works on the FSO moiety, Chou et al. explored the phenylbenzo[b]phosphindole 5-oxide-containing polymer $\mathbf{P 6 8}$ (Figure 8), which exhibited the highest AQY of $14.92 \%$ at $420 \mathrm{~nm}$ due to its suitable light absorption range [84].

\section{Cyano-containing conjugated polymers}

As summarized above, the $\mathrm{D}-\mathrm{A}$ architecture is a fundamental design principle toward high-performance polymer-based photocatalysts, and selecting proper donor and acceptor components significantly influences the eventual photocatalytic activity. Apart from the aforementioned acceptors, the cyano moiety as a strong electron-withdrawing group, has been widely used to design organic semiconductors for diverse applications, such as organic solar cells [85], organic light-emitting diodes [86], and organic field-effect transistors [87]. Researchers have also incorporated cyano moieties into the design of D-A polymers for PHP applications. For instance, Zhuang et al. [88] developed several cyano-substituted porous polymers, which, however, only led to moderate HERs, such as P71 (Figure 9) with a HER of $45.4 \mu \mathrm{mol} \cdot \mathrm{h}^{-1}$ under visible light. Subsequently, Wang et al. reported two olefin-linked, cyano-substituted, benzene-1,3,6,8tetrephenylpyrene-based 2D polymers (P73 and P74). P74 rendered a higher HER of $106 \mu \mathrm{mol} \cdot \mathrm{h}^{-1}(50 \mathrm{mg})$ than $\mathbf{P 7 3}$ $\left(68 \mu \mathrm{mol} \cdot \mathrm{h}^{-1}, 50 \mathrm{mg}\right)$ due to the strongly electron-withdrawing 3-ethylrhodanine fragments in the periphery [89].

\section{CP-based heterojunctions for PHP applications}

Besides D-A polymers, heterojunctions between CPs and other semiconductors have also been developed to facilitate the intermolecular charge transfer and transport. The interactions between the CPs and various semiconductors in the heterojunctions could involve strong covalent bonds, ionic bonds, or hydrogen bonds $[90,91]$. Researchers have also attempted to use heterojunctions as photocatalysts for PHP. For example, Wang et al. combined a pyrene-based polymer (P75) (Figure 10) with g- $\mathrm{C}_{3} \mathrm{~N}_{4}$ to form a heterojunction [92]. The interface between P75 and $\mathrm{g}_{-} \mathrm{C}_{3} \mathrm{~N}_{4}$ restrained charge recombination and promoted proton reduction. Peng et al. also prepared a photocatalyst with a surficial heterojunction composed of P76 (Figure 10) and g- $\mathrm{C}_{3} \mathrm{~N}_{4}$ by facile rotary evaporation [93]. Using ascorbic acid as the sacrificial agent, the AQY of the heterojunction increased to $59.4 \%$ at $500 \mathrm{~nm}$. It suggests that polymer/polymer heterojunctions could effectively improve the intermolecular charge transfer and suppress charge recombination. In addition, Tian et al. developed a series of polymer/polymer heterojunctions with $\mathrm{CPs}$ and $\mathrm{g}_{-} \mathrm{C}_{3} \mathrm{~N}_{4}$ [94]. In particular, the heterojunction between benzotriazole-fluorene-based P77 (Figure 10) and $\mathrm{g}-\mathrm{C}_{3} \mathrm{~N}_{4}$ endowed a high AQT of $33.5 \%$ at $450 \mathrm{~nm}$.

Inspire by the architectures of organic solar cells, Cooper et al. selected a ITIC-based polymer as acceptor and a BT-carbazolebased one as donor to form polymer/polymer heterojunctions 


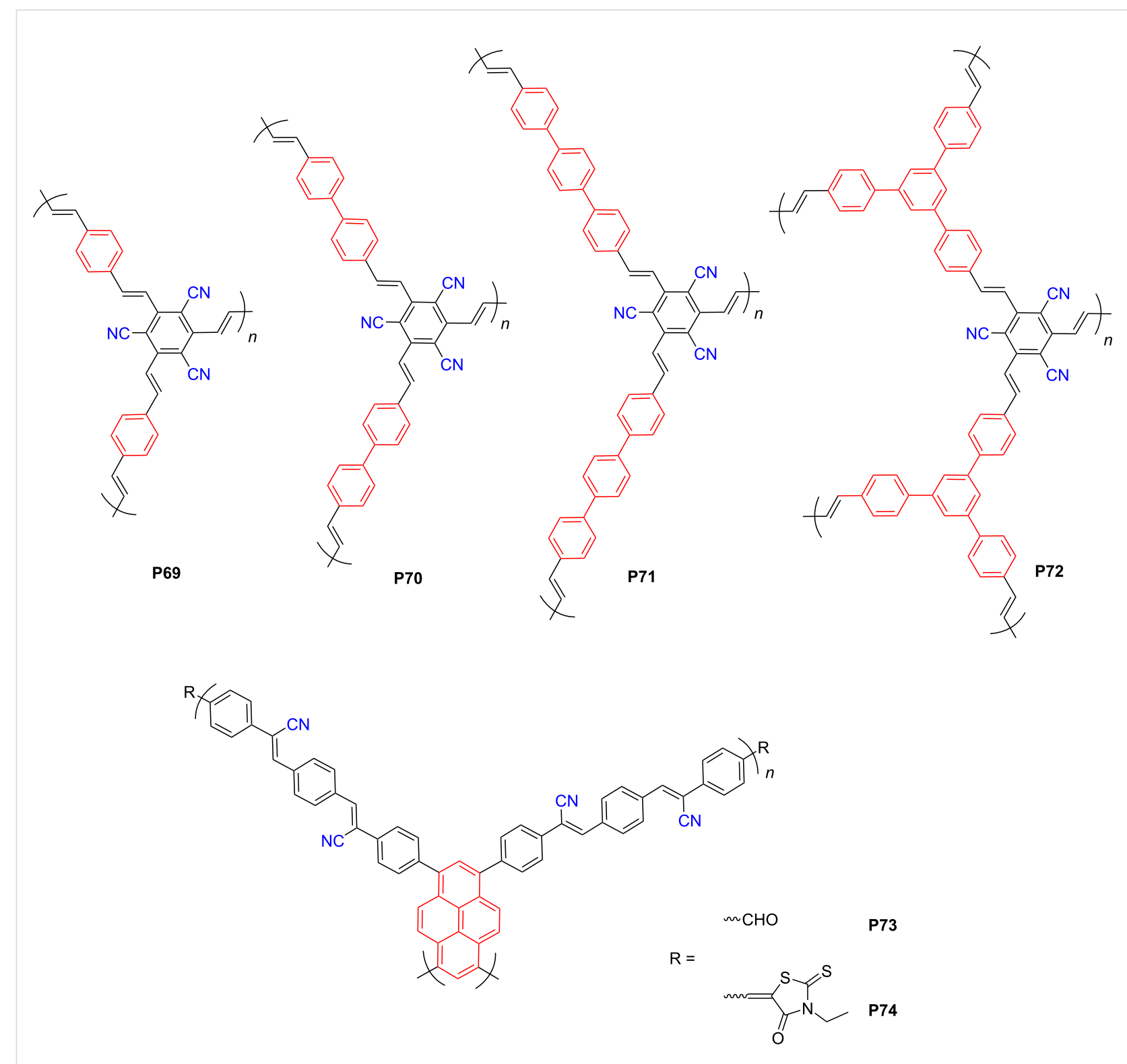

Figure 9: Schematic representation of structures of cyano-based CPs.

[95]. Due to the formation of abundant donor-acceptor interfaces, P78/P79 (Figure 10) exhibited the highest HER of $191.82 \mu \mathrm{mol} \cdot \mathrm{h}^{-1}$ (1.15 mg) [95]. Recently, McCulloch and co-workers discovered another D/A heterojunction (P80/P81) (Figure 10) as photocatalyst for hydrogen evolution. By stabilizing the surfactant employed during synthesis of the heterojunction, ITIC-containing P80 as the acceptor could intimately blend with the donor P81, which rendered HERs up to $128.85 \mu \mathrm{mol} \cdot \mathrm{h}^{-1}$ (2 mg) [96].

Regarding heterojunctions with $\mathrm{TiO}_{2}$, for instance, Hua et al. used two indeno[1,2-b]thiophene-based organic dyes (P82 and P83) (Figure 10) to sensitize $\mathrm{TiO}_{2}$ to harvest near-infrared light
[97]. Consequently, the average HERs of $\mathbf{P 8 2} / \mathrm{TiO}_{2}$ and $\mathbf{P 8 3} / \mathrm{TiO}_{2}$ with $\mathrm{Pt}$ as cocatalyst dramatically increased to 11.3 and 3.9 times, respectively, as high as that of using $\mathrm{TiO}_{2}$ only. Chen et al. attempted to incorporate several CPs, that is, P37, P40, and P84 (Figure 5 and Figure 10), with $\mathrm{TiO}_{2}$ and formed binary composites [98-100]. Compared with pristine CPs as photocatalysts, the photocatalytic activities of the heterojunctions increased by around 18, 7, and 2 times, respectively. Subsequently, the same research group developed a $\mathbf{P 4 0}$ flake/CdS heterojunction with broad visible light absorption (400-700 nm) and high photogenerated charge separation rate [101]. This heterojunction realized an AQY of up to $7.5 \%$ at $420 \mathrm{~nm}$. By in situ solvothermal growth of CdS nanoparticles 


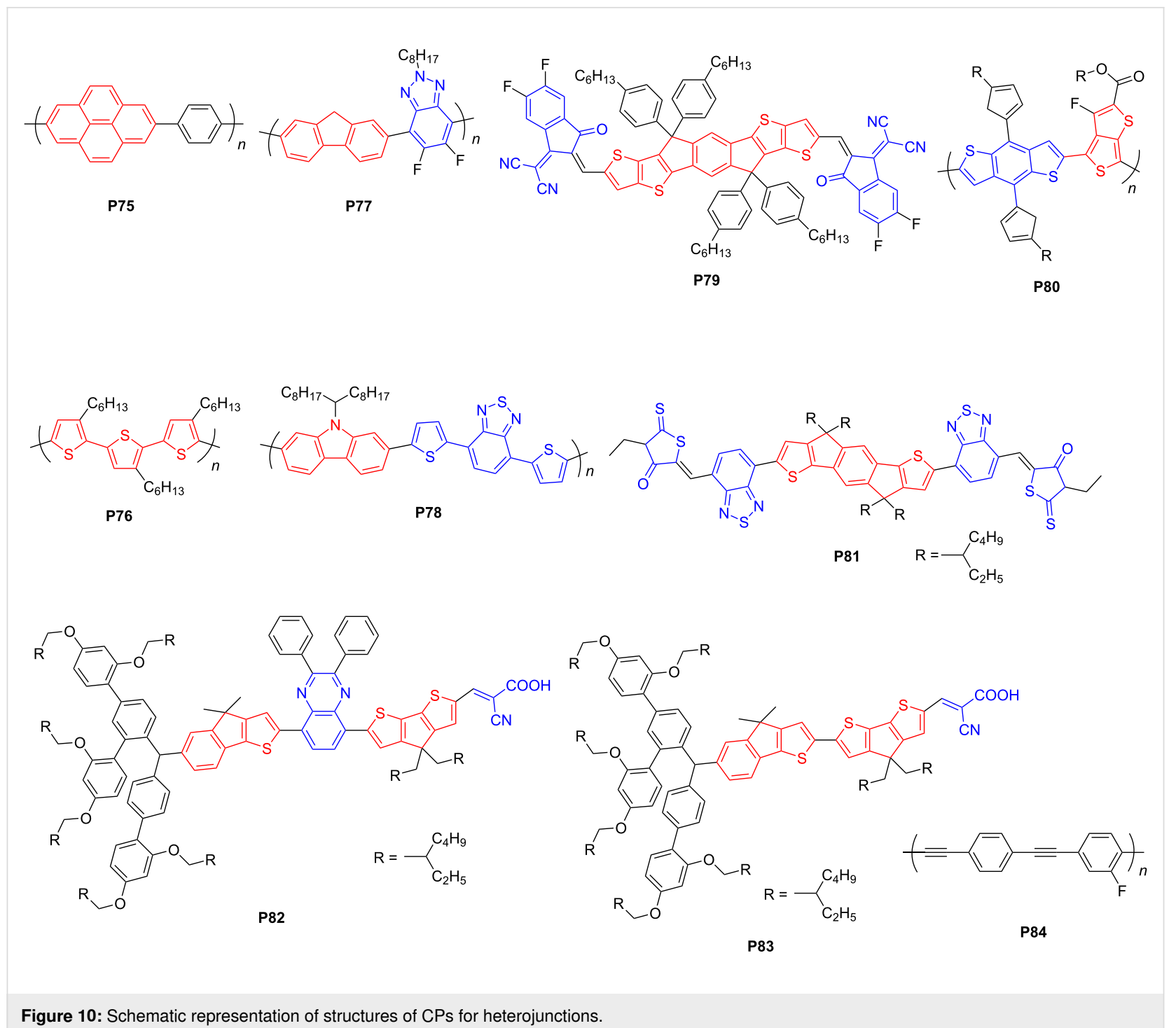

on ultrathin polyimide (PI) nanosheets, Zou et al. [102] achieved a HER of $30.65 \mu \mathrm{mol} \mathrm{h}-1$ (50 mg) with $15 \% \mathrm{CdS} / \mathrm{PI}$ as the photocatalyst, which was nearly 5 and 60 times as high as the performance of pristine $\mathrm{CdS}$ and $1 \% \mathrm{Pt} / \mathrm{PI}$, respectively. This suggests that organic/inorganic heterojunctions show higher photocatalytic performance than the single components of CPs.

Table 1 summarizes the main optoelectronic properties and HERs of the CP-based photocatalysts introduced in this review article.

\section{Conclusion}

Donor-acceptor interactions facilitate the ICT effect and decrease the optical bandgaps of D-A polymers. Correspondingly, they improve both charge carrier mobility and light harvesting, which makes D-A polymers potential photocatalysts for hydro- gen production from water. In this minireview article, we systematically summarized the recent developments of the emerging diverse D-A polymers as photocatalysts for hydrogen evolution by water splitting. Several key messages could be concluded: (1) Architectures with multiple kind of acceptors, for example, D-A-A can improve the HER compared with simple D-A structures. (2) Incorporating heteroatoms, such as $\mathrm{N}, \mathrm{S}$, and $\mathrm{O}$, into the polymer backbone can effectively modulate the physicochemical properties of the polymers. (3) Attaching side chains or functional groups, such as FSO and cyano groups, not only improve the solubility of CPs in water, but also tune the photoelectric properties of the polymers. Although the properties of CPs can be easily mediated by choosing different D and A building blocks, a good counterbalance between narrow bandgap and enough thermodynamic driving force for proton reduction is still hard to achieve for a single CP component. 
Table 1: Summary of the bandgaps, cocatalysts, and properties related to $\mathrm{H}_{2}$ evolution of quintessential CP photocatalysts.

\begin{tabular}{|c|c|c|c|c|c|c|c|c|}
\hline CPs & Bandgap (eV) & LUMO/HOMO (eV) & Cocatalyst & SED & $\operatorname{HER}\left(\mu \mathrm{mol} \cdot \mathrm{h}^{-1}\right)$ & $\operatorname{HER}\left(\mu \mathrm{mol} \cdot \mathrm{g}^{-1} \cdot \mathrm{h}^{-1}\right)$ & AQY (\%) & Ref. \\
\hline P1 & 2.17 & $-0.86 / 1.31$ & $\mathrm{Pt}$ & TEOA & $538^{a}$ & $10760^{\mathrm{a}}$ & 4.07 & [45] \\
\hline P3 & 2.21 & - & $\mathrm{Pt}$ & TEOA & ca. $2.90^{b}$ & ca. $290^{b}$ & - & [46] \\
\hline P4 & 2.16 & - & $\mathrm{Pt}$ & TEOA & $9.15^{\mathrm{b}}$ & $915 \pm 10^{b}$ & - & [47] \\
\hline P5 & 1.99 & - & $\mathrm{Pt}$ & TEOA & $32^{b}$ & $1600^{\mathrm{b}}$ & - & [48] \\
\hline P8 & 2.11 & $-0.76 / 1.35$ & $\mathrm{Pt}$ & TEOA & $966^{a}$ & $19320^{\mathrm{a}}$ & 22.8 & [49] \\
\hline P9 & 2.33 & $-0.42 / 1.91$ & $\mathrm{Pt}$ & TEOA & $50^{\mathrm{a}}$ & $1000^{a}$ & 3.6 & [50] \\
\hline P11 & 2.37 & $-0.44 / 1.93$ & $\mathrm{Pt}$ & TEOA & $22^{\mathrm{a}}$ & $440^{\mathrm{a}}$ & 1.43 & [51] \\
\hline P13 & 2.1 & - & $\mathrm{Pt}$ & TEOA & $0.42^{\mathrm{C}}$ & $83.83^{c}$ & 4.15 & [53] \\
\hline P15 & 2.4 & $-0.90 / 1.5$ & - & TEA & $7.2^{\mathrm{C}}$ & $2057^{C}$ & - & [54] \\
\hline P18 & 2.45 & - & $\mathrm{Pt}$ & TEA & $6.5^{\mathrm{a}}$ & $1857^{\mathrm{a}}$ & 0.34 & [55] \\
\hline P29 & ca. 1.9 & ca. $-1.88 / 0.7$ & - & TEA & $106.9^{c}$ & $8908.3^{C}$ & - & [56] \\
\hline P30 & 2.53 & $-1.00 / 1.33$ & $\mathrm{Pt}$ & TEOA & $18.7^{d}$ & $374^{d}$ & 1.1 & [57] \\
\hline P32 & 1.94 & $-0.8 / 1.14$ & $\mathrm{Pt}$ & TEOA & $0.98^{\mathrm{C}}$ & $98^{\mathrm{C}}$ & - & [58] \\
\hline P33 & 2.32 & $-1.3 / 0.9$ & - & TEOA & $9.73^{a}$ & $2780^{a}$ & 9.60 & [62] \\
\hline P34 & 1.85 & $-0.39 / 1.46$ & $\mathrm{Pt}$ & TEOA & $42^{b}$ & $4200^{b}$ & 1.5 & [63] \\
\hline P35 & 1.76 & $-0.96 / 0.8$ & - & $\mathrm{AA}$ & $19.68^{b}$ & $656^{\mathrm{b}}$ & - & [64] \\
\hline P37 & 2.17 & $-0.89 / 1.28$ & $\mathrm{Pt}$ & TEOA & $116^{a}$ & $2320^{a}$ & 4.01 & [65] \\
\hline P39 & 2.12 & $-0.55 / 1.57$ & - & TEOA & $399^{a}$ & $13300^{\mathrm{a}}$ & 5.7 & [66] \\
\hline P44 & 2.36 & $-1.58 / 0.78$ & $\mathrm{Pt}$ & AA & $177.50^{\mathrm{a}}$ & $8875^{a}$ & 8.45 & [67] \\
\hline P45 & 2.21 & $-1.00 / 1.22$ & $\mathrm{Pt}$ & TEOA & $29.6^{a}$ & $296^{a}$ & - & [68] \\
\hline P48 & 1.69 & $-0.76 / 0.93$ & - & $\mathrm{AA}$ & $32^{\mathrm{a}}$ & $12800^{\mathrm{a}}$ & 0.3 & [69] \\
\hline P49 & 1.98 & $-0.90 / 1.08$ & - & $A A$ & $150^{\mathrm{a}}$ & $50000^{a}$ & 0.6 & [70] \\
\hline P53 & 1.97 & $-0.82 / 1.15$ & - & $A A$ & $16.8^{\mathrm{a}}$ & $840^{\mathrm{a}}$ & 0.9 & [71] \\
\hline P54 & 2.70 & - & - & TEOA & $92^{\mathrm{a}}$ & $3680^{a}$ & - & [74] \\
\hline P56 & 3.64 & $-1.77 / 1.87$ & - & TEOA & $170^{\mathrm{a}}$ & $3400^{a}$ & 6.8 & [75] \\
\hline P57 & 2.07 & $-0.99 / 1.06$ & - & TEA & $50.4^{\mathrm{a}}$ & $5040^{a}$ & 2.31 & [76] \\
\hline P63 & 2.56 & - & - & TEA & $77.65^{a}$ & $3106^{a}$ & 13.2 & [77] \\
\hline P64 & 2.37 & $-1.02 / 1.35$ & $\mathrm{Pt}$ & TEOA & $284.85^{a}$ & $5697^{a}$ & 6.1 & [78] \\
\hline P65 & 2.99 & $-1.86 / 1.15$ & - & TEA & $147.1^{\mathrm{a}}$ & $5884^{a}$ & - & [79] \\
\hline P64 & 2.31 & $-1.06 / 1.80$ & - & TEOA & $400^{a}$ & $8000^{a}$ & 8.5 & [80] \\
\hline P66 & 1.95 & $-0.85 / 1.10$ & - & TEOA & $366^{a}$ & $12200^{a}$ & 3.7 & [81] \\
\hline P67 & 1.85 & - & $\mathrm{Pt}$ & $\mathrm{AA}$ & $252.5^{a}$ & $10100^{a}$ & 0.6 & [83] \\
\hline P68 & 2.88 & $-1.79 / 1.09$ & - & TEA & $30.66^{b}$ & $6132^{b}$ & 14.92 & [84] \\
\hline P71 & 2.12 & $-0.62 / 1.52$ & $\mathrm{Pt}$ & TEOA & $45.4^{\mathrm{a}}$ & $910^{\mathrm{a}}$ & 2 & [88] \\
\hline P74 & 2.03 & $-0.69 / 1.34$ & $\mathrm{Pt}$ & TEOA & $106^{a}$ & $2120^{a}$ & 0.48 & [89] \\
\hline
\end{tabular}

aLight source: $\lambda>420 \mathrm{~nm}$; blight source: $\lambda>400 \mathrm{~nm}$; Clight source: full-arc irradiation; dight source: $\lambda>300 \mathrm{~nm}$.

In this respect, the combination of CPs with other semiconductors to form heterojunctions can further enhance the catalytic performance. Fabricating inorganic/polymer composites with complementary absorption ranges is an efficient strategy to extend the light-responsive region and offer enough thermodynamic driving force compared to single semiconductors. Besides, molecular heterostructures produced by two covalently bonded polymers could be a promising strategy because of effective charge carrier separation and small interfacial charge transfer resistance [103].
Consequently, we envisage the diverse kinds of CPs, in conjunction with inorganic semiconductors, promise enormous potential in PHP applications in the near future. Nevertheless, there is still a large potential for further improving D-A-type CPs for PHP applications. Large-scale and low-cost production of D-A CPs still remains a substantial challenge. Seeking atomand step-economic synthetic alternatives [104] to traditional $\mathrm{C}-\mathrm{M} / \mathrm{C}-\mathrm{Br}(\mathrm{M}=\mathrm{B}$ or $\mathrm{Sn})$ coupling for preparing CPs ought to be a common goal. Furthermore, besides the PHP activity, studies regarding the long-term stability of CPs are still needed. 


\section{ORCID ${ }^{\circledR}$ iDs}

Shi-Yong Liu - https://orcid.org/0000-0002-3569-3826

\section{References}

1. Jayakumar, J.; Chou, H.-H. ChemCatChem 2020, 12, 689-704. doi:10.1002/cctc.201901725

2. Tachibana, Y.; Vayssieres, L.; Durrant, J. R. Nat. Photonics 2012, 6, 511-518. doi:10.1038/nphoton.2012.175

3. Hammarström, L.; Hammes-Schiffer, S. Acc. Chem. Res. 2009, 42, 1859-1860. doi:10.1021/ar900267k

4. Fujishima, A.; Honda, K. Nature 1972, 238, 37-38. doi:10.1038/238037a0

5. Maeda, K.; Domen, K. J. Phys. Chem. C 2007, 111, 7851-7861. doi:10.1021/jp070911w

6. Tong, H.; Ouyang, S.; Bi, Y.; Umezawa, N.; Oshikiri, M.; Ye, J. Adv. Mater. (Weinheim, Ger.) 2012, 24, 229-251. doi:10.1002/adma.201102752

7. Luo, S.; Zeng, Z.; Zeng, G.; Liu, Z.; Xiao, R.; Xu, P.; Wang, H.; Huang, D.; Liu, Y.; Shao, B.; Liang, Q.; Wang, D.; H, e. Q.; Qin, L.; Fu, Y. J. Mater. Chem. A 2020, 8, 6434-6470. doi:10.1039/d0ta01102a

8. Vilela, F.; Zhang, K.; Antonietti, M. Energy Environ. Sci. 2012, 5, 7819-7832. doi:10.1039/c2ee22002d

9. Lee, J.-S. M.; Cooper, A. I. Chem. Rev. 2020, 120, 2171-2214. doi:10.1021/acs.chemrev.9b00399

10. Banerjee, T.; Podjaski, F.; Kroger, J.; Biswal, B. P.; Lotsch, B. V. Nat. Rev. Mater. 2021, 6, 168-190. doi:10.1038/s41578-020-00254-z

11. Yanagida, S.; Kabumoto, A.; Mizumoto, K.; Pac, C.; Yoshino, K. J. Chem. Soc., Chem. Commun. 1985, 474-475. doi:10.1039/c39850000474

12. Wang, X.; Maeda, K.; Thomas, A.; Takanabe, K.; Xin, G.; Carlsson, J. M.; Domen, K.; Antonietti, M. Nat. Mater. 2009, 8, 76-80. doi:10.1038/nmat2317

13. Wang, X.; Blechert, S.; Antonietti, M. ACS Catal. 2012, 2, 1596-1606. doi:10.1021/cs300240x

14. Schwinghammer, K.; Tuffy, B.; Mesch, M. B.; Wirnhier, E.; Martineau, C.; Taulelle, F.; Schnick, W.; Senker, J.; Lotsch, B. V. Angew. Chem., Int. Ed. 2013, 52, 2435-2439. doi:10.1002/anie.201206817

15. Sui, Y.; Liu, J.; Zhang, Y.; Tian, X.; Chen, W. Nanoscale 2013, 5, 9150-9155. doi:10.1039/c3nr02413j

16. Fu, J.; Tian, Y.; Chang, B.; Xi, F.; Dong, X. J. Mater. Chem. 2012, 22 , 21159-21166. doi:10.1039/c2jm34778d

17. Zhang, J.; Zhang, M.; Sun, R.-Q.; Wang, X. Angew. Chem., Int. Ed. 2012, 51, 10145-10149. doi:10.1002/anie.201205333

18. Zhang, J.; Chen, X.; Takanabe, K.; Maeda, K.; Domen, K.; Epping, J. D.; Fu, X.; Antonietti, M.; Wang, X. Angew. Chem., Int. Ed. 2010, 49, 441-444. doi:10.1002/anie.200903886

19. Zhang, J.; Zhang, G.; Chen, X.; Lin, S.; Möhlmann, L.; Dołęga, G.; Lipner, G.; Antonietti, M.; Blechert, S.; Wang, X. Angew. Chem., Int. Ed. 2012, 51, 3183-3187. doi:10.1002/anie.201106656

20. Zhang, G.; Wang, X. J. Catal. 2013, 307, 246-253. doi:10.1016/j.jcat.2013.07.026

21. Zhang, J.; Sun, J.; Maeda, K.; Domen, K.; Liu, P.; Antonietti, M.; Fu, X.; Wang, X. Energy Environ. Sci. 2011, 4, 675-678. doi:10.1039/c0ee00418a

22. Jiang, L.; Yuan, X.; Pan, Y.; Liang, J.; Zeng, G.; Wu, Z.; Wang, H. Appl. Catal., B 2017, 217, 388-406. doi:10.1016/j.apcatb.2017.06.003
23. Wang, Y.; Di, Y.; Antonietti, M.; Li, H.; Chen, X.; Wang, X. Chem. Mater. 2010, 22, 5119-5121. doi:10.1021/cm1019102

24. Lau, V. W.; Moudrakovski, I.; Botari, T.; Weinberger, S.; Mesch, M. B.; Duppel, V.; Senker, J.; Blum, V.; Lotsch, B. V. Nat. Commun. 2016, 7, 12165. doi:10.1038/ncomms12165

25. Sprick, R. S.; Jiang, J.-X.; Bonillo, B.; Ren, S.; Ratvijitvech, T.; Guiglion, P.; Zwijnenburg, M. A.; Adams, D. J.; Cooper, A. I. J. Am. Chem. Soc. 2015, 137, 3265-3270. doi:10.1021/ja511552k

26. Sprick, R. S.; Bonillo, B.; Sachs, M.; Clowes, R.; Durrant, J. R.; Adams, D. J.; Cooper, A. I. Chem. Commun. 2016, 52, 10008-10011. doi:10.1039/c6cc03536a

27. Wang, L.; Wan, Y.; Ding, Y.; Niu, Y.; Xiong, Y.; Wu, X.; Xu, H. Nanoscale 2017, 9, 4090-4096. doi:10.1039/c7nr00534b

28. Woods, D. J.; Sprick, R. S.; Smith, C. L.; Cowan, A. J.; Cooper, A. I. Adv. Energy Mater. 2017, 7, 1700479. doi:10.1002/aenm.201700479

29. Zong, X.; Miao, X.; Hua, S.; An, L.; Gao, X.; Jiang, W.; Qu, D.; Zhou, Z.; Liu, X.; Sun, Z. Appl. Catal., B 2017, 211, 98-105. doi:10.1016/j.apcatb.2017.04.033

30. Sprick, R. S.; Aitchison, C. M.; Berardo, E.; Turcani, L.; Wilbraham, L.; Alston, B. M.; Jelfs, K. E.; Zwijnenburg, M. A.; Cooper, A. I. J. Mater. Chem. A 2018, 6, 11994-12003. doi:10.1039/c8ta04186e

31. Bi, J.; Fang, W.; Li, L.; Wang, J.; Liang, S.; He, Y.; Liu, M.; Wu, L. Macromol. Rapid Commun. 2015, 36, 1799-1805. doi:10.1002/marc.201500270

32. Schwinghammer, K.; Hug, S.; Mesch, M. B.; Senker, J.; Lotsch, B. V. Energy Environ. Sci. 2015, 8, 3345-3353. doi:10.1039/c5ee02574e

33. Kuecken, S.; Acharjya, A.; Zhi, L.; Schwarze, M.; Schomacker, R.; Thomas, A. Chem. Commun. 2017, 53, 5854-5857. doi:10.1039/c7cc01827d

34. Stegbauer, L.; Schwinghammer, K.; Lotsch, B. V. Chem. Sci. 2014, 5, 2789-2793. doi:10.1039/c4sc00016a

35. Cheng, J.-Z.; Liu, L.-L.; Liao, G.; Shen, Z.-Q.; Tan, Z.-R.; Xing, Y.-Q.; Li, X.-X.; Yang, K.; Chen, L.; Liu, S.-Y. J. Mater. Chem. A 2020, 8, 5890-5899. doi:10.1039/c9ta13514f

36. Cheng, C.; Wang, X.; Lin, Y.; He, L.; Jiang, J.-X.; Xu, Y.; Wang, F. Polym. Chem. 2018, 9, 4468-4475. doi:10.1039/c8py00722e

37. Xu, C.; Zhang, W.; Tang, J.; Pan, C.; Yu, G. Front. Chem. (Lausanne, Switz.) 2018, 6, 592. doi:10.3389/fchem.2018.00592

38. Zhang, G.; Lan, Z.-A.; Wang, X. Angew. Chem., Int. Ed. 2016, 55, 15712-15727. doi:10.1002/anie.201607375

39. Schroeder, B. C.; Li, Z.; Brady, M. A.; Faria, G. C.; Ashraf, R. S.; Takacs, C. J.; Cowart, J. S.; Duong, D. T.; Chiu, K. H.; Tan, C.-H.; Cabral, J. T.; Salleo, A.; Chabinyc, M. L.; Durrant, J. R.; McCulloch, I. Angew. Chem., Int. Ed. 2014, 53, 12870-12875. doi:10.1002/anie.201407310

40. Gu, C.; Huang, N.; Chen, Y.; Zhang, H.; Zhang, S.; Li, F.; Ma, Y.; Jiang, D. Angew. Chem., Int. Ed. 2016, 55, 3049-3053. doi:10.1002/anie.201510723

41. Wang, L.; Fernández-Terán, R.; Zhang, L.; Fernandes, D. L. A.; Tian, L.; Chen, H.; Tian, H. Angew. Chem., Int. Ed. 2016, 55, 12306-12310. doi:10.1002/anie.201607018

42. Damas, G. B.; Marchiori, C. F. N.; Araujo, C. M. J. Phys. Chem. C 2019, 123, 25531-25542. doi:10.1021/acs.jpcc.9b06057

43. Martin, D. J.; Reardon, P. J. T.; Moniz, S. J. A.; Tang, J. J. Am. Chem. Soc. 2014, 136, 12568-12571. doi:10.1021/ja506386e

44. Liu, G.; Wang, T.; Zhang, H.; Meng, X.; Hao, D.; Chang, K.; Li, P.; Kako, T.; Ye, J. Angew. Chem., Int. Ed. 2015, 54, 13561-13565. doi:10.1002/anie.201505802 
45. Guo, L.; Niu, Y.; Xu, H.; Li, Q.; Razzaque, S.; Huang, Q.; Jin, S.; Tan, B. J. Mater. Chem. A 2018, 6, 19775-19781. doi:10.1039/c8ta07391k

46. Schwarz, D.; Kochergin, Y. S.; Acharjya, A.; Ichangi, A.; Opanasenko, M. V.; Čejka, J.; Lappan, U.; Arki, P.; He, J.; Schmidt, J.; Nachtigall, P.; Thomas, A.; Tarábek, J.; Bojdys, M. J. Chem. - Eur. J. 2017, 23, 13023-13027. doi:10.1002/chem.201703332

47. Schwarz, D.; Acharja, A.; Ichangi, A.; Lyu, P.; Opanasenko, M. V.; Goßler, F. R.; König, T. A. F.; Čejka, J.; Nachtigall, P.; Thomas, A.; Bojdys, M. J. Chem. - Eur. J. 2018, 24, 11916-11921. doi:10.1002/chem.201802902

48. Kailasam, K.; Mesch, M. B.; Möhlmann, L.; Baar, M.; Blechert, S.; Schwarze, M.; Schröder, M.; Schomäcker, R.; Senker, J.; Thomas, A. Energy Technol. 2016, 4, 744-750. doi:10.1002/ente.201500478

49. Guo, L.; Niu, Y.; Razzaque, S.; Tan, B.; Jin, S. ACS Catal. 2019, 9, 9438-9445. doi:10.1021/acscatal.9b01951

50. Yu, J.; Sun, X.; Xu, X.; Zhang, C.; He, X. Appl. Catal., B 2019, 257, 117935. doi:10.1016/j.apcatb.2019.117935

51. Yu, J.; Chang, S.; Xu, X.; He, X.; Zhang, C. J. Mater. Chem. C 2020, 8, 8887-8895. doi:10.1039/d0tc00942c

52. Matsuoka, S.; Kohzuki, T.; Kuwana, Y.; Nakamura, A.; Yanagida, S. J. Chem. Soc., Perkin Trans. 2 1992, 679-685. doi:10.1039/p29920000679

53. Haase, F.; Banerjee, T.; Savasci, G.; Ochsenfeld, C.; Lotsch, B. V. Faraday Discuss. 2017, 201, 247-264. doi:10.1039/c7fd00051k

54. Li, L.; Cai, Z. Polym. Chem. 2016, 7, 4937-4943. doi:10.1039/c6py00972g

55. Li, L.; Cai, Z.; Wu, Q.; Lo, W.-Y.; Zhang, N.; Chen, L. X.; Yu, L. J. Am. Chem. Soc. 2016, 138, 7681-7686. doi:10.1021/jacs.6b03472

56. Li, L.; Lo, W.-y.; Cai, Z.; Zhang, N.; Yu, L. Macromolecules 2016, 49, 6903-6909. doi:10.1021/acs.macromol.6b01764

57. Wang, Z.; Mao, N.; Zhao, Y.; Yang, T.; Wang, F.; Jiang, J.-X. Polym. Bull. 2019, 76, 3195-3206. doi:10.1007/s00289-018-2535-3

58. Stegbauer, L.; Zech, S.; Savasci, G.; Banerjee, T.; Podjaski, F.; Schwinghammer, K.; Ochsenfeld, C.; Lotsch, B. V. Adv. Energy Mater. 2018, 8, 1703278. doi:10.1002/aenm.201703278

59. Liu, H.; Zhang, X.-F.; Cheng, J.-Z.; Zhong, A.-G.; Wen, H.-R.; Liu, S.-Y. Molecules 2019, 24, 1760. doi:10.3390/molecules24091760

60. Liu, S.-Y.; Liu, H.; Shen, Z.-Q.; Huang, W.-Y.; Zhong, A.-G.; Wen, H.-R. Dyes Pigm. 2019, 162, 640-646. doi:10.1016/j.dyepig.2018.10.075

61. Zhang, X.-F.; Cheng, J.-Z.; Liu, H.; Shan, Q.; Jia, G.-X.; Wen, H.-R.; Liu, S.-Y. Dyes Pigm. 2020, 172, 107819. doi:10.1016/j.dyepig.2019.107819

62. Xiao, W.-J.; Wang, Y.; Wang, W.-R.; Li, J.; Wang, J.; Xu, Z.-W.; Li, J.; Yao, J.; Li, W.-S. Macromolecules 2020, 53, 2454-2463. doi:10.1021/acs.macromol.9b02488

63. Liu, Y.; Liao, Z.; Ma, X.; Xiang, Z. ACS Appl. Mater. Interfaces 2018, 10, 30698-30705. doi:10.1021/acsami.8b10022

64. Xu, M.; Kong, K.; Ding, H.; Chu, Y.; Zhang, S.; Yu, F.; Ye, H.; Hu, Y.; Hua, J. J. Mater. Chem. C 2020, 8, 930-934. doi:10.1039/c9tc04175c

65. Yang, C.; Ma, B. C.; Zhang, L.; Lin, S.; Ghasimi, S.; Landfester, K.; Zhang, K. A. I.; Wang, X. Angew. Chem., Int. Ed. 2016, 55, 9202-9206. doi:10.1002/anie.201603532

66. Xiang, Y.; Wang, X.; Rao, L.; Wang, P.; Huang, D.; Ding, X.; Zhang, X.; Wang, S.; Chen, H.; Zhu, Y. ACS Energy Lett. 2018, 3, 2544-2549. doi:10.1021/acsenergylett.8b01535
67. Chen, W.; Wang, L.; Mo, D.; He, F.; Wen, Z.; Wu, X.; Xu, H.; Chen, L. Angew. Chem., Int. Ed. 2020, 59, 16902-16909. doi:10.1002/anie.202006925

68. Xu, Y.; Mao, N.; Zhang, C.; Wang, X.; Zeng, J.; Chen, Y.; Wang, F.; Jiang, J.-X. Appl. Catal., B 2018, 228, 1-9. doi:10.1016/j.apcatb.2018.01.073

69. Hu, Z.; Wang, Z.; Zhang, X.; Tang, H.; Liu, X.; Huang, F.; Cao, Y. iScience 2019, 13, 33-42. doi:10.1016/j.isci.2019.02.007

70. Pati, P. B.; Damas, G.; Tian, L.; Fernandes, D. L. A.; Zhang, L.; Pehlivan, I. B.; Edvinsson, T.; Araujo, C. M.; Tian, H. Energy Environ. Sci. 2017, 10, 1372-1376. doi:10.1039/c7ee00751e

71. Zhao, P.; Wang, L.; Wu, Y.; Yang, T.; Ding, Y.; Yang, H. G.; Hu, A. Macromolecules 2019, 52, 4376-4384. doi:10.1021/acs.macromol.9b00551

72. Damas, G. B.; von Kieseritzky, F.; Hellberg, J.; Marchiori, C. F. N.; Araujo, C. M. J. Phys. Chem. C 2019, 123, 30799-30808. doi:10.1021/acs.jpcc.9b07721

73. Bai, Y.; Wilbraham, L.; Slater, B. J.; Zwijnenburg, M. A.; Sprick, R. S.; Cooper, A. I. J. Am. Chem. Soc. 2019, 141, 9063-9071. doi:10.1021/jacs.9b03591

74. Sprick, R. S.; Bonillo, B.; Clowes, R.; Guiglion, P.; Brownbill, N. J.; Slater, B. J.; Blanc, F.; Zwijnenburg, M. A.; Adams, D. J.; Cooper, A. I. Angew. Chem., Int. Ed. 2016, 55, 1792-1796. doi:10.1002/anie.201510542

75. Lan, Z.-A.; Zhang, G.; Chen, X.; Zhang, Y.; Zhang, K. A. I.; Wang, X. Angew. Chem., Int. Ed. 2019, 58, 10236-10240. doi:10.1002/anie.201904904

76. Dai, C.; Xu, S.; Liu, W.; Gong, X.; Panahandeh-Fard, M.; Liu, Z.; Zhang, D.; Xue, C.; Loh, K. P.; Liu, B. Small 2018, 14, 1801839. doi:10.1002/smll.201801839

77. Sprick, R. S.; Bai, Y.; Guilbert, A. A. Y.; Zbiri, M.; Aitchison, C. M.; Wilbraham, L.; Yan, Y.; Woods, D. J.; Zwijnenburg, M. A.; Cooper, A. I. Chem. Mater. 2019, 31, 305-313. doi:10.1021/acs.chemmater.8b02833

78. Zhao, Y.; Ma, W.; Xu, Y.; Zhang, C.; Wang, Q.; Yang, T.; Gao, X.; Wang, F.; Yan, C.; Jiang, J.-X. Macromolecules 2018, 51, 9502-9508. doi:10.1021/acs.macromol.8b02023

79. Bai, Y.; Woods, D. J.; Wilbraham, L.; Aitchison, C. M.; Zwijnenburg, M. A.; Sprick, R. S.; Cooper, A. I. J. Mater. Chem. A 2020, 8, 8700-8705. doi:10.1039/d0ta02599b

80. Lan, Z.-A.; Ren, W.; Chen, X.; Zhang, Y.; Wang, X. Appl. Catal., B 2019, 245, 596-603. doi:10.1016/j.apcatb.2019.01.010

81. Wang, X.; Chen, B.; Dong, W.; Zhang, X.; Li, Z.; Xiang, Y.; Chen, H. Macromol. Rapid Commun. 2019, 40, 1800494. doi:10.1002/marc.201800494

82. Sprick, R. S.; Cheetham, K. J.; Bai, Y.; Alves Fernandes, J.; Barnes, M.; Bradley, J. W.; Cooper, A. I. J. Mater. Chem. A 2020, 8 , 7125-7129. doi:10.1039/d0ta01200a

83. Wang, X.; Chen, L.; Chong, S. Y.; Little, M. A.; Wu, Y.; Zhu, W.-H.; Clowes, R.; Yan, Y.; Zwijnenburg, M. A.; Sprick, R. S.; Cooper, A. I. Nat. Chem. 2018, 10, 1180-1189. doi:10.1038/s41557-018-0141-5

84. Wang, W.-H.; Ting, L.-Y.; Jayakumar, J.; Chang, C.-L.; Lin, W.-C.; Chung, C.-C.; Elsayed, M. H.; Lu, C.-Y.; Elewa, A. M.; Chou, H.-H. Sustainable Energy Fuels 2020, 4, 5264-5270. doi:10.1039/d0se00928h

85. Patil, Y.; Misra, R. Chem. - Asian J. 2018, 13, 220-229. doi:10.1002/asia.201701493

86. Uoyama, H.; Goushi, K.; Shizu, K.; Nomura, H.; Adachi, C. Nature 2012, 492, 234-238. doi:10.1038/nature11687 
87. Jones, B. A.; Facchetti, A.; Marks, T. J.; Wasielewski, M. R. Chem. Mater. 2007, 19, 2703-2705. doi:10.1021/cm0704579

88. Bi, S.; Lan, Z.-A.; Paasch, S.; Zhang, W.; He, Y.; Zhang, C.; Liu, F.; Wu, D.; Zhuang, X.; Brunner, E.; Wang, X.; Zhang, F. Adv. Funct. Mater. 2017, 27, 1703146. doi:10.1002/adfm.201703146

89. Jin, E.; Lan, Z.; Jiang, Q.; Geng, K.; Li, G.; Wang, X.; Jiang, D. Chem 2019, 5, 1632-1647. doi:10.1016/j.chempr.2019.04.015

90. Hu, B. J.; Sun, Q.; Zuo, C. Y.; Pei, Y. X.; Yang, S. W.; Zheng, H.; Liu, F. M. Beilstein J. Nanotechnol. 2019, 10, 1157-1165. doi:10.3762/bjnano.10.115

91. Kaushik, A.; Kumar, R.; Arya, S. K.; Nair, M.; Malhotra, B. D.; Bhansali, S. Chem. Rev. 2015, 115, 4571-4606. doi:10.1021/cr400659h

92. Zang, S.; Zhang, G.; Yang, P.; Zheng, D.; Wang, X. Chem. - Eur. J. 2019, 25, 6102-6107. doi:10.1002/chem.201900414

93. Zhang, X.; Peng, B.; Zhang, S.; Peng, T. ACS Sustainable Chem. Eng. 2015, 3, 1501-1509. doi:10.1021/acssuschemeng.5b00211

94. Ye, H.; Wang, Z.; Yu, F.; Zhang, S.; Kong, K.; Gong, X.; Hua, J.; Tian, H. Appl. Catal., B 2020, 267, 118577. doi:10.1016/j.apcatb.2019.118577

95. Yang, H.; Li, X.; Sprick, R. S.; Cooper, A. I. Chem. Commun. 2020, 56, 6790-6793. doi:10.1039/d0cc00740d

96. Kosco, J.; Bidwell, M.; Cha, H.; Martin, T.; Howells, C. T.; Sachs, M.; Anjum, D. H.; Gonzalez Lopez, S.; Zou, L.; Wadsworth, A.; Zhang, W.; Zhang, L.; Tellam, J.; Sougrat, R.; Laquai, F.; DeLongchamp, D. M.; Durrant, J. R.; McCulloch, I. Nat. Mater. 2020, 19, 559-565. doi:10.1038/s41563-019-0591-1

97. Ding, H.; Xu, M.; Zhang, S.; Yu, F.; Kong, K.; Shen, Z.; Hua, J. Renewable Energy 2020, 155, 1051-1059. doi:10.1016/j.renene.2020.04.009

98. Hou, H.-J.; Zhang, X.-H.; Huang, D.-K.; Ding, X.; Wang, S.-Y.; Yang, X.-L.; Li, S.-Q.; Xiang, Y.-G.; Chen, H. Appl. Catal., B 2017, 203, 563-571. doi:10.1016/j.apcatb.2016.10.059

99. Xiang, Y.; Wang, X.; Zhang, X.; Hou, H.; Dai, K.; Huang, Q.; Chen, H. J. Mater. Chem. A 2018, 6, 153-159. doi:10.1039/c7ta09374h

100.Chen, B.; Wang, X.; Dong, W.; Zhang, X.; Rao, L.; Chen, H.; Huang, D.; Xiang, Y. Chem. - Eur. J. 2019, 25, 3362-3368. doi:10.1002/chem.201805740

101.Zhang, X.; Xiao, J.; Hou, M.; Xiang, Y.; Chen, H. Appl. Catal., B 2018, 224, 871-876. doi:10.1016/j.apcatb.2017.11.038

102.Hu, Y.; Hao, X.; Cui, Z.; Zhou, J.; Chu, S.; Wang, Y.; Zou, Z. Appl. Catal., B 2020, 260, 118131. doi:10.1016/j.apcatb.2019.118131

103. Huang, W.; He, Q.; Hu, Y.; Li, Y. Angew. Chem., Int. Ed. 2019, 58, 8676-8680. doi:10.1002/anie.201900046

104.Huang, W.-Y.; Shen, Z.-Q.; Cheng, J.-Z.; Liu, L.-L.; Yang, K.; Chen, X.; Wen, H.-R.; Liu, S.-Y. J. Mater. Chem. A 2019, 7, 24222-24230. doi:10.1039/c9ta06444c

\section{License and Terms}

This is an Open Access article under the terms of the Creative Commons Attribution License (https://creativecommons.org/licenses/by/4.0). Please note that the reuse, redistribution and reproduction in particular requires that the author(s) and source are credited and that individual graphics may be subject to special legal provisions.

The license is subject to the Beilstein Journal of Nanotechnology terms and conditions: (https://www.beilstein-journals.org/bjnano/terms)

The definitive version of this article is the electronic one which can be found at: https://doi.org/10.3762/bjnano.12.50 